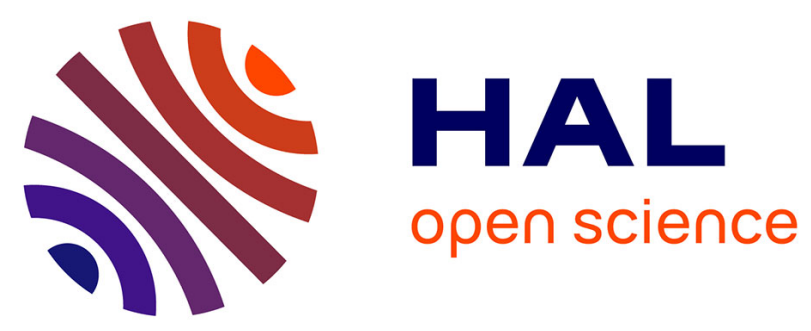

\title{
The Regulation of Carbon and Nutrient Assimilation in Diatoms is significantly different from Green Algae
} Christian Wilhelm, Claudia Büchel, Joachim Fisahn, Reimund Goss, Torsten Jakob, Julie Laroche, Johann Lavaud, Martin Lohr, Ulf Riebesell, Katja Stehfest, et al.

\section{To cite this version:}

Christian Wilhelm, Claudia Büchel, Joachim Fisahn, Reimund Goss, Torsten Jakob, et al.. The Regulation of Carbon and Nutrient Assimilation in Diatoms is significantly different from Green Algae. Protist, 2006, 157, pp.91-124. 10.1016/j.protis.2006.02.003 . hal-01094652v2

\section{HAL Id: hal-01094652 \\ https://hal.science/hal-01094652v2}

Submitted on 19 Dec 2014

HAL is a multi-disciplinary open access archive for the deposit and dissemination of scientific research documents, whether they are published or not. The documents may come from teaching and research institutions in France or abroad, or from public or private research centers.
L'archive ouverte pluridisciplinaire HAL, est destinée au dépôt et à la diffusion de documents scientifiques de niveau recherche, publiés ou non, émanant des établissements d'enseignement et de recherche français ou étrangers, des laboratoires publics ou privés. 
Title page

The Regulation of Carbon and Nutrient Assimilation in Diatoms is significantly different from Green Algae.

Christian Wilhelm ${ }^{1}$, Claudia Büchel ${ }^{2}$, Joachim Fisahn ${ }^{3}$, Reimund Goss ${ }^{1}$, Torsten Jakob ${ }^{1}$, Julie LaRoche $^{4}$, Johann Lavaud ${ }^{5}$, Martin Lohr ${ }^{6}$, Ulf Riebesell ${ }^{4}$, Katja Stehfest ${ }^{1}$, Klaus Valentin ${ }^{7}$ and Peter G. Kroth ${ }^{5}$

${ }^{1}$ University of Leipzig, Institute of Biology I, Department of Plant Physiology, 04103 Leipzig, Johannisallee 23, Germany

${ }^{2}$ Johann Wolfgang Goethe-Universität, Botanisches Institut, Siesmayerstraße 70, D-60439 Frankfurt, Germany

${ }^{3}$ Max Planck Institut für Molekulare Pflanzenphysiologie, Am Mühlenberg 1, D-14476 Golm, Germany

${ }^{4}$ Leibniz-Institut für Meereswissenschaften, Marine Biogeochemie; Düsternbrooker Weg 20; D-24105 Kiel, Germany

${ }^{5}$ Universität Konstanz, Fachbereich Biologie, D-78457 Konstanz, Germany

${ }^{6}$ Johannes Gutenberg-Universität, Institut für Allgemeine Botanik, D-55099 Mainz, Germany

${ }^{7}$ Alfred-Wegener-Institut für Polar- und Meeresforschung, Am Handelshafen 12, D-27570 Bremerhaven, Germany

Running Title: Primary Metabolisms of Diatoms

Corresponding author:

Christian Wilhelm, Fax: \#49 341 9736899, email: cwilhelm@rz.uni-leipzig.de 


\section{Abstract}

Diatoms are important primary producers not only in the oceans but also in the freshwater environment. The efficiency of biomass formation strongly depends on the metabolic regulation of carbon and nutrient assimilation. Recent studies have given evidence that many metabolic regulations are quite different from green algae and higher plants. The major known differences concern the following processes: (1) pigment biosynthesis, (2) lightharvesting organisation, (3) mechanism of photoprotection, (4) regulation of photosynthetic electron flow, (5) regulation of the enzyme activity in the Calvin-Benson cycle, (6) photorespiration, (7) carbon aquisition and $\mathrm{CO}_{2}$-concentrating mechanisms, (8) synthesis and breakdown of storage products under starvation, (8) nutrient uptake (9) adaptation to extreme environments. This review summarises these differences phenomenologically and presents the actual knowledge of the underlying mechanisms. The availability of whole genome sequence data is an important basis to learn in more detail how photosynthesis in these tremendously successful primary producers is regulated.

Key words: $\quad$ carbon aquisition, biomass composition, diatoms, genome, photosynthesis, photorespiration, nutrient uptake 
Abbreviations: ACCase: acetyl-CoA-carboxylase; AGPase: ADP-glucose pyrophosphorylase; AMT; ammonium transporter family; Ax: Antheraxanthin; CA: carboanhydrase; Car: carotenoid; CCM: carbon concentrating mechanism; Chl: chlorophyll; CP: chlorophyll protein; DDE: Diadinoxanthin-De-epoxidase; DEP: Diatoxanthin-Epoxidase; Ddx: diadinoxanthin; DPOR: light-independent NADP:protochlorophyllide oxidoreductase; Dtx: diatoxanthin; EPS: extracellular polymeric substances; FCP: fucoxanthin-chlorophyll-protein; FBA: Fructose-bisphosphate; FBPase: Fructosebisphosphatase; FTR: Ferredoxin-thioredoxinreductase; GAP-DH: glyceraldehyde-dehydrogenase; LHC: light-harvesting complex; MGDG: Monogalactosyldiacylglycerate; NPQ: non-photochemical quenching; NR: nitrate reductase; OPP: oxidative pentosephosphate cycle; PEPC: phosphorenolpyruvate carboxylase; PEPCK: phosphoenolpyruvate carboxykinase; PHOX: alkaline phosphatase; PPDK: pyruvate orthophosphate dikinase; PRK: Phosphoribulokinase; PQ: plastoquinone; PSI: photosystem I; PSII: photosystem II; ROS: reactive oxygen species; SBPase: Seduheptulose-1,7bisphosphatase; TR: thioredoxin; XC: xanthophyll cycle; VDE: Violaxanthin-De-epoxidase; Vx: violaxanthin; Zx: zeaxanthin; ZEP: zeaxanthin epoxidase. 


\section{Introduction}

Diatoms are the major players in the biochemical cycles of carbon, nitrogen, phosphorus and silicon with a strong impact on global climate not only in the ocean but also in the freshwater environment. In the ocean they tend to dominate the phytoplankton assemblage under nutrient rich conditions, whereas in the freshwater ecosystems high turbulence and the combination of low temperature/high nutrient favour diatom blooming. Their fascinating biodiversity with approximately 10,000 species has been recently taxonomically revised giving evidence that the diatoms form two clades: the Coscinodiscophycideae and the Bacillariophytina, the latter containing two subclades Bacillariophyceae and Mediophyceae; all the more this tremendous species diversity evolved during the last $250 \mathrm{Ma}$ and there is no phylogenetic group in which the evolutionary rate occurred faster (Medlin and Kaszmarska 2004). Therefore, the diatoms can be considered as one of the most successful taxonomic groups with respect to evolution and ecology. The genetic and physiological basis why diatoms became such ecologically successful careerists is still a matter of debate.

The recently published genome of Thalassiosira pseudonana (Armbrust et al. 2004) and the EST sequence data available from Phaeodactylum tricornutum (Maheswari et al. 2005) have opened new perspectives in diatom research to understand in more detail their physiological peculiarities. The metabolism in oxygenic phototrophs depends on gene expression processes coordinated between the three different compartments, the nucleus, the plastid and the mitochondrion. Diatoms originate from a secondary endosymbiotic event (see Figure 1) as opposed to the primary endosymbiotic origin of the "Chloroplastida" including the Charophyta, Chlorodendrales, Chlorophyta, Mesostigma and Prasinophytae as defined in Adl et al. (2005).

There is convincing evidence that the ancestral diatom derived from a putatively nonphotosynthetic eukaryote which domesticated a eukaryotic cell phylogenetically close to a red 
alga: this "red line phylogenetics is clearly a work in progress" (Palmer 2003), because we do neither know the nature of the secondary host nor whether all "chromophytes" originate from one single endocytobiotic event (Patron et al. 2004). Gene analyses based on whole genome sequencing of $T$. pseudonana showed that the diatom genome contains about 800 proteins which align with proteins of animals but do not have homologues in the genome of Arabidopsis thaliana and the red alga Cyanidioschyzon merolae (Armbrust et al 2004). This suggests that in diatoms the cytosolic metabolic pathways might be closer related to an animal-like than to a plant-like cell, which would be likely to affect the physiological regulation of photosynthesis. Looking at the obligatory intracellular gene transfer in chromophytic phototrophs from the vanishing nucleus of the endosymbiont to the nucleus of the secondary host cell, various genes for proteins involved in photosynthesis had to be integrated into the new, more animal-like nucleus. Therefore, we have to expect a different pattern in the nucleome-chondriome-plastome interaction with the consequence that metabolic pathways related to these compartments had been lost or that the respective genes had been transferred to the nucleus of the secondary endosymbiont. Therefore, the plastid had to develop completely new interaction pattern with his genetic partners. This regulatory network in diatoms is not yet understood.

The stabilisation of a secondary endosymbiosis did not only require the development of protein targeting from the cytosol into the plastids crossing four membranes (Kilian and Kroth 2004), but also required a signal exchange in the reverse direction from the organelle to the nucleus. In the last few years it has been shown in green cells that photosynthesis-related nuclear genes are under chloroplast redox control by a new class of plastid signals (Goldschmidt-Clermont 1998). The sensor for this signal is the redox state of the plastoquinone pool which depends on the relative activity of photosystem II and photosystem I. However, the redox state of the chloroplast does not only depend on membrane-bound reactions, but also on the oxidative state of the stroma being under control of the system 
including thioredoxin (TR), gluthathione, ascorbate and their related metabolizing enzymes. Although the biochemical nature of this retrograde signalling is still not identified, the importance of this redox-controlled nuclear gene expression has recently been shown by Fey et al. (2005) demonstrating that this signal triggers the whole cellular network of gene expression. This retrograde plastid to nucleus signalling must be basically different in green algae and diatoms because of two reasons. First, the cooperating nuclei are of different phylogenetic origin and second the redox control in green algae and diatoms is found to be basically different as outlined below (see chapters 5 and 6 below)

However we do not know, what had been the consequences of the secondary endocytobiosis on the metabolic regulations and if the physiological peculiarities of diatoms observed in the past reflect this different host-endosymbiont relationship. Here in this review we concentrate on cell functions which clearly separate the diatoms physiologically from algae of the chloroplastidic lineage.

- The thylakoid membranes in diatoms are arranged in groups of three and are not differentiated into grana/stroma lamellae (Owens 1988; Berkaloff et al. 1990) having consequences not only for the PSII/PSI ratio, the regulation of the wavelengthdependent energy distribution between both photosystems via so-called state 1-state 2 transitions but also for the redox signalling (Owens 1986).

- The light-harvesting proteins of diatoms are not differentiated into minor and major complexes and the protein domains which trigger membrane stacking in Chloroplastida by modulation of phosphorylation do not exist (Larkum and Vesk 2003, Westermann and Rhiel 2005).

- In Chloroplastida photoprotection is supported by cycling of xanthophylls bound to the minor antenna proteins in the presence of a special proteins encoded by the psbS gene. In diatoms xanthophylls even more contribute to the photoprotection, however, 
in the genome of $T$. pseudonana neither a psbS gene nor genes encoding for minor light-harvesting units could be identified.

- Diatoms lack the $\alpha$-carotene pathway with the consequence that photoprotective and light-harvesting pigments are synthesized on the same metabolic branch asking for quite intelligent mechanisms of regulation (Lohr and Wilhelm 1999)

- In contrast to Chloroplastida metabolic activity in long dark periods leads to enhanced reduction state of the plastoquinone pool which is accompanied by the build-up of a proton gradient strong enough to drive the de-epoxidation reaction of xanthophyll cycle pigments (Jakob et al. 1999). Here again the impact of unusual redox control of gene expression is obvious.

- In chloroplasts of the Chloroplastida the activity of enzymes of the photosynthetic dark reactions is regulated by light via the redox state of thiolgroups. There is now evidence that in diatoms the Calvin cycle is controlled by a different mechanism and that the oxidative pentose phosphate cycle is not present (Michels et al. 2005).

- It has been observed that inhibitory effects of high concentration of oxygen/low concentration of $\mathrm{CO}_{2}$ on photosynthetic activity are less pronounced in diatoms than in green algae (Beardall 1989). This has been discussed in the light of an active transport and accumulation of inorganic carbon within the cell (Beardall 1989) and the C4 fixation metabolism in diatoms (Reinfelder et al. 2004). However, some crucial plastid-localised enzymes being prerequisites in this metabolic pathway could not be identified in the diatom genome.

- The metabolic carbon flow in diatom photorespiration is not yet elucidated. However, there is clear evidence that in diatoms the photorespiratory carbon flux is not coupled to the nitrogen flux as in the typical carbon-oxidation cycle in green algae. Surprisingly, the genome analysis of $T$. pseudonana has evidenced that in contrast to 
green algae the diatoms possess a complete set of genes for a functional urea cycle (Armbrust et al. 2004). In this context it might be noteworthy that the genes encoding for the enzymes for ß-oxidation and catalase could be found in the genome (Armbrust et al. 2004), however, it is not yet clear if this pathway is located in the peroxisome.

- Diatoms synthesize as energy storage products lipids and the $\beta-1,3$ glycan chrysolaminarin. In contrast to starch the $\beta$-polymer does not form crystals. In green algae the carbon storage product starch induces cell sinking, whereas in diatoms the storage product lipid can increase the cell’s buoyancy.

- Julie please check, see reviewer comment 6:Diatoms have the ability to adapt their Fe:C ratio in a wide range indicating that the metabolism can specificylly adopt to iron limitation (LaRoche et al. 1996). Recent data from genome sequence analysis gave evidence for the existence of a complete set of high-affinity uptake transporters in diatoms.

- Diatoms can grow in sea ice forming a biomass up to $1000 \mu \mathrm{g}$ chlorophyll per litre, a value which is reached only in hypertrophic waters or in extremely eutrophicated sediments (Thomas and Dieckmann 2002). The molecular and physiological reasons for significant growth at $0^{\circ} \mathrm{C}$ and survival at temperatures below $-20{ }^{\circ} \mathrm{C}$ are still a matter of debate (Mock and Valentin 2004).

In this paper we concentrate on genes and functions which are involved in the energy flow from light to biomass known to be different between diatoms and green algae and discuss these pecularities in the light of the recently obtained full genome information

\section{Biosynthesis of photosynthetic pigments}


The first step in the conversion of light into biomass is the capture of light energy by pigments. In Chloroplastida, the Chls $a$ and $b$ are the major light-harvesting pigments. The carotenoids lutein, neoxanthin, violaxanthin $(\mathrm{Vx})$ and $\beta$-carotene contribute to lightharvesting only to a limited extend, while their main function is photoprotection (Bassi and Caffarri 2000). In diatoms, Chl $b$ is replaced by $c$-type Chls, which lack the aliphatic phytol side chain and thus are much more polar. In general, diatoms contain two different Chl $c$ species, Chl $c_{1}$ and Chl $c_{2}$ (Jeffrey 1989). However, a survey of 51 diatom strains showed that in some diatoms $\mathrm{Chl} c_{1}$ is substituted by $\mathrm{Chl} c_{3}$ while in rare cases even all three $\mathrm{Chl} c$-species are present (Stauber and Jeffrey 1988).

With respect to carotenoids, diatoms contain only xanthophylls which are derived from $\beta$ carotene, they are not capable of making carotenoids with $\varepsilon$-ionon rings like $\alpha$-carotene or lutein (Pennington et al. 1988). The dominant carotenoid and major light-harvestingxanthophyll in diatoms is fucoxanthin, which is characterised by an allenic group at one end and a keto group near the other end of the central isoprenoid chain (see Fig. 2 and 3). Other carotenoids present in significant amounts are $\beta$-carotene and the acetylenic xanthophylls diadinoxanthin (Ddx) and diatoxanthin (Dtx) (Stauber and Jeffrey 1988; Pennington et al. 1988), which constitute the major xanthophyll cycle in diatoms (see below).

The presence of $\mathrm{Chl} a$ and $\beta$-carotene is shared by all photosynthetic eukaryotes and cyanobacteria, implying that the general biosynthetic pathways were inherited from the cyanobacterial ancestor of all extant plastids. In Chloroplastida, the biochemistry and molecular genetics of the biosynthetic pathways leading to the formation of Chls (as reviewed in Beale 1999; Vavilin and Vermaas, 2002; Eckhardt et al. 2004) and carotenoids (see, e.g., Cunningham and Gantt 1998; Hirschberg 2001) have been extensively studied, and genes have been identified for most of the enzymes known to be directly involved. With a few exceptions all the biosynthetic proteins are nucleus-encoded and contain presequences that 
target them to the plastids. Recently, the genome of the green alga $C$. reinhardti has been analysed in detail for the presence of respective homologues (Grossman et al. 2004; Lohr et al. 2005).

For diatoms, biochemical data on enzymatic reactions leading to the formation of Chls and carotenoids are limited. In $S$. costatatum, the activity of 5-aminolevulinic acid dehydratase has been examined (Owens et al. 1978), and some studies on the turnover of Chls were conducted in both S. costatum (Riper et al. 1979) and T. weissflogii (Goericke and Welschmeyer 1992b). For the biosynthesis of the $c$-type Chls, only hypothetical pathways have been proposed so far. Chl $c_{2}$ may be formed from divinyl-protochlorophyllide by desaturation of the propionic acid side chain at ring $\mathrm{D}$, while $\mathrm{Chl} c_{1}$ could result from the same desaturation reaction but using protochlorophyllide as substrate. Chls $c_{1}$ and $c_{2}$ might be interconvertible by reversible saturation of the vinyl group at ring B of Chl $c_{2}$ (Porra 1997; Beale 1999; see also Figure. 2). Like Chloroplastida, the chromophyte algae appear to use the plastid-localised methylerythritol-phosphate (MEP) pathway - also known as deoxy-xylulose-phosphate (DOXP) pathway - for formation of carotenoids as well as the phytol moiety of Chl a., as has been demonstrated for the chrysophyte Ochromonas danica (Dish et al. 1998). In case of diatoms, this has been confirmed only for phytol (Cvejić and Rohmer 2000; Massé et al. 2004; carotenoids were not investigated in these studies). Labeling kinetics of carotenoids in T. weissflogii suggested that Ddx is a precursor of fucoxanthin (Goericke and Welschmeyer 1992b). Therefore, unlike Chloroplastida, diatoms can utilize part of the photoprotective xanthophyll-cycle pigments which accumulate under high-light conditions for the formation of the major light-harvesting xanthophyll fucoxanthin in subsequent low light (Lohr and Wilhelm 1999). This was corroborated by analyses of the pigment conversion kinetics in two other diatoms, P. tricornutum and C. meneghiniana, which also implied that $\mathrm{Vx}$ and $\mathrm{Ax}$ are intermediates in the formation of Ddx and fucoxanthin (Lohr and Wilhelm 1999; 2001). However, large discrepancies between measured epoxidation kinetics of thylakoid-localised 
Zx and those inferred from a mathematical description of pigment biosynthesis under steadystate conditions suggested, that diatoms may use $\beta$-cryptoxanthin instead of $Z x$ as intermediate in the formation of $\mathrm{Vx}$ from $\beta$-carotene. Alternatively, the observed inconsistencies may be explained by a fast epoxidation of $\mathrm{Zx}$ in the envelope membranes, possibly by an enzyme which is different from the thylakoid-associated epoxidase (Lohr and Wilhelm 2001)

In the recently published genome sequence of T. pseudonana, genes predicted to encode homologues of most of the enzymes known to be directly involved in the biosynthesis of Chls and carotenoids in Chloroplastida are present (Figure 2 and Table 1; see also Table S3 in Armbrust et al. 2004). Only the CHL27 protein, which recently has been identified as a subunit of the Mg-protoporphyrin IX monomethylester cyclase (reviewed in Berthold and Stenmark 2003) has no potential homolog in the current genome version of T. pseudonana. CHL27 is nucleus-encoded in vascular plants and green algae, but encoded on the plastid genome in red algae (Lohr et al. 2005). Since we also failed to detect sequences encoding a CHL27 homolog on the plastomes of T. pseudonana and Odontella sinensis, diatoms might utilize an unrelated enzyme to form the isocyclic ring of their Chls.

The protoporphyrin IX Mg-chelatase subunit CHLI is encoded on the plastid genome of the diatoms O. sinensis (Kowallik et al. 1995) and T. pseudonana (Armbrust et al. 2004) as is the case for green algae (with the exception of $C$. reinhardtii), glaucophytes, red algae, and other heterokont algae examined so far (Valentin et al. 1998; Lohr et al. 2005), whereas it is nucleus-encoded in vascular plants. In green algae, mosses and gymnosperms, the only other plastome-encoded proteins involved in the biosynthesis of Chls are the subunits of the lightindependent protochlorophyllide oxidoreductase (DPOR), namely chlB, chlL and chlN, while angiosperms have lost these genes (Porra 1997; Beale 1999). The plastome of the red alga Porphyra purpurea also harbours the chlB, chlL and chlN genes (Reith and Munholland 
1993). However, the plastid genome of another red alga, Cyanidioschyzon merolae only encodes chlN (Glöckner et al. 2000) while those of Cyanidium caldarium (Ohta et al. 2003) and Gracilaria tenuistipitata (Hagopian et al. 2004) lost all three genes. As for C. caldarium and G. tenuistipitata, no homologues of $c h l B N L$ are present on the plastomes of $O$. sinensis and T. pseudonana, and the nuclear genome of the latter also contains no genes with similarity to the known DPOR-subunits. Nonetheless, observations on transformants of the diatom P. tricornutum which were able to grow heterotrophically suggest that the algae are able to synthezise Chl $a$ not only in light but also in the dark (Zaslavskaia et al. 2001). This implies that diatoms might contain another light-independent protochlorophyllide oxidoreductase which is unrelated to DPOR. Such a proposal hs been made in case of angiosperms previously (Adamson et al. 2000).

Finally, the genome of $T$. pseudonana harbours putative isogenes for a number of enzymatic steps in both pigment pathways which are potential targets for further studies. Concerning the biosynthesis of Chls (Table 1; see also Lohr et al. 2005), the genome contains multiple genes for uroporhyrinogen III decarboxylase, coproporhyrinogen III oxidase, the Mg-chelatase subunit CHLH, the recently discovered divinyl-protochlorophyllide reductase (Nagata et al. 2005), and the light-dependent NADP:protochlorophyllide oxidoreductase. The presence of two closely related copies for divinyl-protochlorophyllide reductase is of particular interest, because one (or both) isozyme(s) may be involved not only in reduction of divinylprotochlorophyllide $a$ but also in formation of $\mathrm{Chl} c_{1}$ from $\mathrm{Chl} c_{2}$ (Figure 2).

In the biosynthetic pathway of carotenoids, putative isozymes are present for isopentenyl diphosphate isomerase (IDI), phytoene synthase (PSY), phytoene desaturase (PDS) and Zx/Dtx epoxidase (ZEP/DEP). Here, the occurrence of potential ZEP isozymes is particularly remarkable, because this may be related to the above mentioned inconsistencies between measured and calculated epoxidation rates of Zx (Lohr and Wilhelm 2001). One ZEP isozyme might localize to the thylakoid membranes and be involved in the xanthophyll cycle, while the 
other could be situated at the envelope membranes. The latter enzyme then might be mainly involved in a linear pathway of de-novo biosynthesis of xanthophylls.

To explore the significance of the putative isozymes in T.pseudonana, their catalytic function, differential expression and cellular localization will have to be examined. Moreover, the genes / proteins responsible for biosynthesis of the c-type Chls and those involved in the late steps of xanthophyll formation in diatoms remain to be discovered.

\section{Light-harvesting organisation}

Higher plants and green algae are the organisms whose intrinsic light-harvesting systems (LHC) are most extensively studied. Functionally, two groups of these pigmented, membrane intrinsic proteins can be distinguished: proteins serving as antenna for PS I or II, encoded by lhca genes or by lhcb genes, respectively. The major LHC, LHCII, is trimeric and mainly associated with PS II. The minor LHCs, located in close vicinity to the PS II core, are monomeric. Antennae specific for PSI, LHCI, assemble into heterodimers and are found at one side of the PS I core. The supramolecular arrangement of antenna proteins and PSs has been studied extensively by e.g. electron microscopy, revealing a clear picture not only of the spatial distribution of proteins but also of their dynamic (for review see Dekker and Boekema 2005). In diatoms, thylakoid membrane arrangement differs significantly from that in Chloroplastida, because the differentiation into PS II-rich grana and PS I-rich stroma thylakoids is completely lacking (Owens 1988). Instead, thylakoids run the whole length of the plastids in bands of three thylakoids each and no segregation of PSs could be detected so far. In addition, no special PS I or PS II antenna could be found (Berkaloff et al. 1990; Brown 1988; Owens and Wold 1986).

Despite these differences in the organisation of thylakoid assembly, light-harvesting systems in diatoms are also membrane intrinsic proteins. Their pigmentation differs considerably and 
thus the absorption capabilities, which have a major influence on photosynthetic performance in different environments (See chapter 3). In fucoxanthin-binding proteins (FCP) $\mathrm{Chl} b$ is replaced by $\mathrm{Chl}$ c, a chlorophyll lacking the aliphatic phytol side chain and thus being much more polar. Additionally, the major carotenoid is fucoxanthin, a carotenoid characterised by a keto group at the isoprenoid chain responsible for the quite unique spectroscopic characteristics only resembled by those of peridinin (found e.g. in dinophytes). One of these features includes an extreme bathochromic shift of absorbance upon up to $60 \mathrm{~nm}$ by binding to the protein, thus being responsible for the brown colour of the antenna proteins and the cells as such. Another, yet unexplained difference between LHCs and FCPs concerns the stoichiometry of the pigments. Whereas LHC bind far more Chl than carotenoid, e.g. $14 \mathrm{Chl}$ and only 4 Car in the case of LHCII, in FCP the Chl to Car ratio is almost one (Papagiannakis et al. 2005). Early sequencing of cDNA clones of the major genes for these antennas in $P$. tricornutum and Cyclotella cryptica found some homology to the LHCII of higher plants, placing these proteins into the same family (Bhaya and Grossman 1993; Eppard and Rhiel 1998). From the sequence three membrane spanning helices were predicted, whereby homology to LHC is mainly found in helix 1 and 3. Generally, FCPs are smaller in size (18$22 \mathrm{kDa}$ ) compared to higher plant LHC, mainly due to shorter loops and termini.

Although no specialised antenna for either PS I or II could be identified biochemically in diatoms so far, some information is available on different genes for FCPs due to the recent efforts in sequencing. In summary, three groups can be distinguished: One group represents the major FCP in diatoms and is closest related to FCPs in nearby algal groups, e.g. brown alga (Green 2003). Fcpl-5 in C. cryptica and $f c p A-F$ in P. tricornutum belong to these genes. The second group of FCP genes is closely related to the one intrinsic light-harvesting protein in red algae, lhca, and to membrane intrinsic antenna in cryptophytes. A member of this group was first detected by Eppard and Rhiel (1998) in C. cryptica $\left(f_{c p} 4\right)$ and later also found in the 
T. pseudonana genome (Armbrust et al. 2004). The last major group is related to a protein found in $C$. reinhardtii but not in higher plants: a light inducible member of the LHC family, LI818. In C. cryptica, fcp 6, 7 and 12 belong to this group (Green 2003). In the P. tricornutum EST data bank sequences representing this type of FCP can also be found (data not shown) and they are also present in the genome of T. pseudonana (Armbrust et al. 2004).

Despite this detailed knowledge about genes and their relation to other genes from the LHC family, biochemical information on FCPs is scarce. A major obstacle might be the instability in the presence of most detergents. In addition, different FCPs show high similarity concerning size, sequence and (probably) pigmentation. This makes the separation of the different proteins extremely difficult. Indeed, up to now two distinguishable FCPs were isolated only in one case from the same organism, C. meneghiniana (Büchel 2003). Interestingly, the oligomeric state differed: the $18 \mathrm{kDa}$ proteins (belonging to the group of major FCPs according to their molecular weight) assembled into trimers, whereas the $19 \mathrm{kDa}$ subunits where arranged in stable higher oligomers. $19 \mathrm{kDa}$ proteins in C. meneghiniana could be either products of $f c p 5$ (major FCP) or the $f c p 6 / 7$ genes (LI818 clade). As no sequencing of the isolated proteins was undertaken, this problem remains unresolved.

One of the most interesting question concerning light-harvesting systems is the mechanism and efficiency of excitation energy transfer. To this end, various spectroscopic methods were applied to higher plant LHCs, ranging from steady state spectroscopy to transient data in the femto second range, yielding a detailed picture of the excitation energy transfer in these complexes. Additionally, mutation of the pigment binding sites helped to attribute spectral features to certain pigments (Rogl et al. 2002). First examinations based on femto second absorption transients of FCPs were published recently (Papagiannakis et al. 2005). These data not only helped to understand the special spectral features of fucoxanthin bound to the protein 
but also lead to the development of a preliminary structural model, based on sequence comparison as well as spectroscopy (Figure 3).

Pigments bound to antenna proteins primarily serve the function of light-harvesting, however, protection against a surplus of light is another role carried out by those proteins (see chapter 4). There was a long debate where the pigments undergoing conversion are located and how psbS, a member of the LHC superfamily predicted to have four helices, is involved. Diatoms posses two xanthophylls cycles, the prominent one consisting of Ddx and Dtx. The overall amount of these pigments is highly variable with culture conditions and an enrichment of the FCP fractions in Ddx in P. tricornutum could be observed under intermittent light regime (Lavaud et al. 2003). Additionally, the fucoxanthin to Chl ratio was decreased in these FCPs. Whether this is due to some replacement of fucoxanthin by Ddx in the same protein or by a change in expression level of a (still to be identified) special Ddx binding FCP has to be elucidated.

To answer questions about the excitation energy transfer, not only spectroscopic data but also high resolution structural data are needed, especially about the arrangement of pigments and thus the orientation of their dipole transition moment. In higher plants, X-ray crystallography has revealed the molecular structure of the LHCI with near atomic resolution, showing the precise location of the protein scaffold as well as every pigment (Liu et al. 2004; Standfuss et al. 2005). Comparable data are completely lacking for FCPs. Several types of FCP are encoded in the genome but could not be separated biochemically so far. Thus, spectroscopic data as well as a real molecular model of these proteins are still missing, hampering a detailed understanding of light harvesting capabilities in diatoms.

\section{Mechanism of photoprotection}


The photosynthetic efficiency and subsequently productivity strongly depend on the light environment which can be highly variable in aquatic ecosystems due to water motions and optical properties (Fogg 1991; MacIntyre et al. 2000; Lichtman and Klausmeir. 2001). Fluctuating irradiances and especially excessive light exposure can be harmful for photosynthesis, in particular to PS II decreasing the fitness of photosynthetic organisms (Külheilm et al. 2002). In order to cope with fluctuating light, diatoms have evolved various mechanisms ensuring photoprotection of their photosynthetic apparatus. The two most important processes for rapid (seconds to tens of minutes) regulation of a switch from a lightharvesting to a photoprotecting state are (Lavaud et al 2002a,c; 2004): 1) the nonphotochemical fluorescence quenching (NPQ), 2) cycling of electrons around PS II and or PSI. These two mechanisms allow PSII to dissipate safely excessively absorbed light energy during a sudden increase in the incident intensity and prolonged exposure to an irradiance which is higher than the capacity of the dark reactions. Diatoms show a higher amplitude for PS II cycling of electrons and for NPQ in comparison to Chloroplastida (Lavaud et al. 2002a; c; Ruban et al. 2004). This has been observed in several diatom species from both freshwater and marine habitats (see Lavaud et al. 2002a, 2004 and citations therein).

In Chloroplastida, where the NPQ mechanism elucidation is a longstanding topic of interest, several regulatory components are necessary for the NPQ to develop, including a transthylakoid proton gradient $(\Delta \mathrm{pH})$, de-epoxidized forms of xanthophylls synthesised via a xanthophyll cycle (XC), and PsbS, a LHC type protein (Holt et al. 2004). Although diatoms share common components, they show some intriguing peculiarities pointing out to a quite different mechanistic NPQ model (Ruban et al. 2004). First, diatoms have a very special LHC organisation whose change in macrodomain organisation is still only partially known (see chapter 2). This holds true for the location of the xanthophylls within the LHC (Lavaud et al. 2003; Guglielmi et al. 2005). Additionally, in diatoms there are no genes coding for some 
important LHC components involved in the Chloroplastida NPQ (PsbS but also CP26 and CP29; Ambrust et al. 2004). Second, diatoms have a different XC which consists in the conversion under an excess of light of the Ddx into its de-epoxidised form, Dtx , and vice versa under limiting light or darkness (see below). The presence of Dtx is mandatory for NPQ (Lavaud et al. 2002a, b; 2004; Ruban et al. 2004) so that in diatoms the NPQ mechanism appears to be more tightly related to the xanthophylls than in their green counterparts. Third, the role played by the $\Delta \mathrm{pH}$ in the regulation of NPQ is still unclear in diatoms. In Chloroplastida, it plays a central role generating the allosteric aggregation of the LHC subunits and the activation of the xanthophylls-dependent quenching (Horton et al. 2000; Holt et al. 2004). In diatoms, there is no clear evidence for a LHC aggregation and the possible effect of Dtx without the $\Delta \mathrm{pH}$ is still controversial (Goss et al. 2006). As a consequence, it has been observed that the relationship between the photochemical activity and the development of NPQ is different in diatoms comparing to green plants (Figure 4). All together, these differences in the regulatory components and mechanistic aspects of the NPQ process in diatoms in comparison to green organisms have been suggested to play an important role in their successful ecological adaptation to turbulent aquatic freshwater and marine habitats in contrast to other eukaryotic algae and to cyanobacteria (Fogg 1991; MacIntyre et al. 2000; Lichtman and Klausmeir 2001; Falkowski et al. 2003; Strzepeck and Harisson 2004).

The correlation between NPQ and the de-epoxidation status can be very different between diatom species (Lavaud et al. 2004; Strzepeck and Harrison 2004). Recently, it has been demonstrated that the capacity for photoprotection depends on both the light environment and the iron availability of the natural habitat (Strzepeck and Harrison 2004, see also chapter 9). Especially, the light fluctuations can drive the spatial distribution of planktonic diatoms confirming earlier observations of a differential photoadaptative response 
of diatom species from different ecosystems, typically coastal and oceanic (Sakshaug et al. 1987; MacIntyre et al. 2000). The very few in situ measurements showed that the NPQ process, as well as the $\mathrm{XC}$, is essential for maintaining the photosynthetic activity of diatoms in an aquatic variable light environment (Müller and Wilhelm 1997; Kashino et al. 2002). Especially, a differential capacity for the XC has been suggested to be involved in species succession (Meyer et al, 2000). Indeed, it appears that under controlled conditions as well as in nature, diatoms seem to be able to regulate their photosynthesis by a fine-tuning of their xanthophyll content in order to maximise their photoprotection capacities without significantly affecting their ability for light-harvesting under light-limiting conditions (Eisner et al. 2003; Lavaud et al. 2003). These observations support the hypothesis that photoprotection might be part of a physiological network ensuring an unusual photosynthetic flexibility and defining the ecological success of diatoms in a turbulent aquatic environment (see chapter 5 on regulation of electron flow).

\section{Properties of the diadinoxanthin (Ddx) cycle enzymes of diatoms}

Diadinoxanthin de-epoxidase (DDE)

The high efficiency of xanthophyll cycling in diatoms is based on special features of the respective enzymes. DDE is the enzyme catalyzing the forward reaction of the Ddx cycle (Figure 5 and Stransky and Hager 1970), which comprises the de-epoxidation of the epoxyxanthophyll Ddx to the epoxy-free Dtx. Under in vivo conditions DDE is activated by the acidification of the thylakoid lumen, which is driven by the light-induced photosynthetic electron transport. Isolated DDE has a pH-optimum at $\mathrm{pH} 5.5$ but enzyme activity can already be observed at neutral pH-values of pH 7.2 (Jakob et al. 2001). This is in contrast to Vx deepoxidase (VDE), the enzmye catalyzing the de-epoxidation sequence from $\mathrm{Vx}$ to $\mathrm{Ax}$ and $\mathrm{Zx}$ in higher plants (Figure 5, Yamamoto et al. 1962). VDE shows a pH-optimum that is shifted 
towards a lower pH-value of 5 (Hager 1969) and, more importantly, enzyme activity cannot be observed at pH-values higher than 6.5 (Hager 1969; Pfündel et al. 1994). Activation of DDE at neutral $\mathrm{pH}$-values has significant consequences for the operation of the Ddx cycle in vivo and the de-epoxidation of Ddx to Dtx can already be triggered by a weak lumen acidification induced by e.g. a chlororespiratory electron flow (Jakob et al. 1999, 2001). During the de-epoxidation sequence DDE, like the VDE of Chloroplastida, requires reduced ascorbate as cosubstrate to reduce the epoxy-group, which is then eliminated as $\mathrm{H}_{2} \mathrm{O}$ (Hager 1969). Recent results (Grouneva et al 2006) suggest that DDE exhibits a significantly reduced apparent $\mathrm{K}_{\mathrm{M}}$-value for its cobsubstrate ascorbate compared to the VDE of higher plants. This allows the enzyme to perform an efficient conversion of Ddx to Dtx not only at higher $\mathrm{pH}$ values but also at much lower concentrations of reduced ascorbate in the thylakoid lumen of the chloroplast. Another important factor for both DDE and VDE activity is the presence of the major thylakoid membrane lipid MGDG (Latowski et al. 2002; Goss et al. 2005). The role of MGDG in xanthophyll de-epoxidation is twofold. MGDG serves to solubilize the xanthophyll cycle pigments Ddx and Vx, thereby providing both pigments in a form, which is accessible by the respective de-epoxidases (Goss et al. 2005). MGDG furthermore forms special three-dimensional structures, the so-called inverted hexagonal phases, which have been shown to be essential for Vx (Latowski et al. 2002) and Ddx de-epoxidation (Goss et al. 2005). Although at present the localization of these $H_{I I}$ domains (an association with the outside of the thylakoid bilayer or special areas within the bilayer are discussed) is not clear, their role in xanthophyll de-epoxidation is undisputable. It has been proposed that the MGDG-rich domains of the thylakoid membrane are the sites, where the de-epoxidases bind to the membrane after their pH-dependent activation (Hager and Holocher 1994). Although enzyme activity of both DDE and VDE equally rely on the presence of MGDG a significant difference in the solubility of the xanthophyll cycle pigments Ddx and Vx has been described (Goss et al. 2005): Ddx is much more readily solubilized in MGDG than Vx, implying that in 
the diatom thylakoid membranes lower MGDG concentrations are sufficient to drive efficient Ddx de-epoxidation or that upon illumination higher amounts of Ddx can detach from the light-harvesting proteins, diffuse to the free lipid phase of the membrane and still be efficiently de-epoxidized. This is in agreement with data from the literature that have shown that the Ddx cycle pigment pool size can be much larger in diatoms compared to the Vx cycle pool size in Chloroplastida (Lavaud et al. 2003).

\section{Dtx epoxidase (DEP)}

DEP is the enzyme catalyzing the back reaction of the Ddx cycle, which comprises the epoxidation of Dtx back to Ddx. DEP has the same cosubstrate requirements as the Zx epoxidase (ZEP) of higher plants (Büch et al. 1995) and uses oxygen, FAD, and NAD(P)H to reintroduce the epoxy-group into the Dtx molecule. DEP like ZEP of Chloroplastida is supposed to be located in the chloroplast stroma and to be active at $\mathrm{pH}$-values around 7.5, which have been described to represent the pH-optimum of the higher plant ZEP (Hager 1975, Siefermann and Yamamoto 1975). There is, however, a significant difference in the regulation of DEP and ZEP. In Chloroplastida epoxidation of Zx is not only observed under conditions of low light illumination or in complete darkness, but also under high light illumination, where even increased rates of pigment conversion can be observed (Siefermann and Yamamoto 1975). DEP, on the other hand, is completely inhibited during high light illumination by the build-up of the transmembrane pH-gradient (Mewes and Richter 2002). At present it is not clear if DEP is down-regulated by the minor $\mathrm{pH}$-change in the chloroplast stroma that occurs during the establishment of the light-driven $\Delta \mathrm{pH}$ or by other factors, which are indirectly coupled to the proton gradient. However, complete DEP inhibition during HL illumination, in conjunction with an activated DDE, ensures a rapid and efficient deepoxidation of Ddx to Dtx. 
Significance of DDE and DEP properties for the photoprotection of diatom cells

In higher plants and green algae multiple photoprotection mechanisms like the Vx cycle, enhanced dissipation of excitation energy at the PS II reaction center, state transitions, alternative electron cycling (see next chapter 5) and D1 protein turnover interact to provide efficient protection against an overexcitation of the photosynthetic apparatus (for a recent review see Stroch et al. 2004). Diatoms, on the other hand, almost completely rely on the Ddx cycle as their main photoprotection mechanism (Lavaud et al. 2002, see chapter 3). The properties of diatom DDE and DEP are significantly different from the homologues enzymes from Chloroplastida and are much better optimised to ensure a rapid and efficient photoprotection.

\section{Regulation of photosynthetic electron flow and the fate of photosynthetic electrons}

The light stimulated photolysis of water at Photosystem II delivers electrons for the production of reducing equivalents and ATP further required in the carbon fixation. However, beside this linear transport of photosynthetic electrons there are several possibilities for electron cycling and divergency of electrons for other reactions (an overview is given in Figure 6). Electron cycling was observed around PSII (involving cytochrome b559; Whitmarsh and Pakrasi 1996) and around PSI. Here, it can be distinguished between a true cycle either from ferredoxin to cytochrome $b_{6} f$ or via NADPH and the plastoquinone pool (Burrows 1998; Endo et al. 1999). The so-called pseudo-cyclic electron transport refers to the reduction of molecular oxygen in the Mehler-reaction (Asada 1996). Torsten: please check and see comment 18: Furthermore, the reduction of nitrite can account for a significant loss of photosynthetic electrons. Under conditions of low $\mathrm{CO}_{2} /$ high $\mathrm{O}_{2}$-pressure within the cells the 
photosynthetically produced NADPH can be consumed for the reduction of oxygen via the oxygenase activity of RubisCO (Ort and Baker 2002). Photorespiration does not only prevent the carbon fixation, additionally, especially in algae the glycolate produced in the oxygenase reaction can be lost completely by excretion (Leboulanger et al. 1998; see also chapter 7). All these pathways diverging from the linear transport can be denoted as alternative electron pathways. In higher plants alternative electron pathways can consume up to $30 \%$ of the photosynthetically derived electrons (Asada 1999; Badger et al. 2000; Wingler et al. 2000). Torsten: please check and see comment 20: In diatoms the PSII-cycle (Lavaud et al. 2002c), the Mehler-reaction (Claquin et al. 2004) and photorespiration (Schnitzler-Parker \& Armbrust, 2004) appear to be significant, although there are no reliable data about the activity of the distinct alternative electron pathways in this algal class so far. However, from laboratory measurements (Gilbert et al. 2000) and in situ-approaches (Jakob et al. 2005) it is evident that the general activity of alternative electron pathways in diatoms is rather low. This was further approved in a comparison of the diatom $P$. tricornutum and the green alga Chlorella vulgaris under simulated natural light regimes (Wagner et al. 2006). Under fluctuating light conditions a much higher conversion efficiency of photosynthetic energy into biomass was observed in the diatom compared to the green alga. This was mainly due to the high loss of photosynthetic electrons in $C$. vulgaris by alternative electron pathways. However, in a non-fluctuating light regime these differences disappeared in the efficiency of biomass production between the diatom and the green alga. Under these conditions a higher activity of alternative electron pathways was found also in the diatom. Alternative electron cycling in green algae seems to be a less efficient mechanism of energy dissipation than strong xanthophylls-dependent NPQ in diatoms. These findings support the ecological success of diatoms in turbulent waters (see chapters 3 and 4).

Besides the alternative consumption of electrons as described above there is also the possibility that electrons from cellular metabolism can be introduced in the electron transport 
chain via the $\mathrm{NAD}(\mathrm{P}) \mathrm{H}$-dehydrogenase due to a high reductant pressure. Characteristically for this process is the occurrence of chlororespiratory activity. Chlororespiration denotes a respiratory pathway in the chloroplast which involves an electron transport from $\mathrm{NAD}(\mathrm{P}) \mathrm{H}$ to oxygen via the PQ-pool and is active in darkness, only (Bennoun 1982). In higher plants this electron pathway becomes relevant during chromoplast development (Carol et al. 1999) and might be understood as a metabolic remnant of the prokaryotic ancestor of the plastid. Unicellular algae, however, are expected to sustain prolonged dark periods and chlororespiration could be auxiliary in the regenerative cycling of energy equivalents and also in the regulation of catabolic reactions in the chloroplast. Diatoms are known for their high potential to survive very long dark periods with a high growth rate upon a return to light (Murphy and Cowles 1997). As suggested by Armbrust et al. (2004) diatoms could take advantage from the high quantities of storage lipids which can serve for gluconeogenesis and the generation of ATP under these conditions. Concurrently with the oxidation of fatty acids, the necessity of a recycling of energy equivalents (via chlororespiration) might arise. In the diatoms $P$. tricornutum and $C$. meneghiana a strong reduction of the PQ-pool was found after $48 \mathrm{~h}$ in darkness (data not shown). The chlororespiratory proton gradient was shown to be high enough to activate the de-epoxidation reaction of the xanthophyll cycle (Jakob et al. 1999; see also chapter 3). In the green alga C. reinhardtii, although known to have the chlororespiratory pathway, such a high reduced state of the thylakoid membrane after prolonged dark periods was never observed. In $C$. reinhardtii chlororespiration and the related increase in the redox state of PQ is usually induced after inhibition of mitochondrial respiration or by nutrient deprivation (Bennoun 1994; Peltier and Schmidt 1991). Nevertheless, neither the electron donor to PQ nor the terminal acceptor is not yet identified in diatoms.

Indication for a strong stromal reductant pressure in diatoms was also deduced from the PSI re-reduction kinetics with a half-time comparable to the cyanobacteria (Grouneva et 
al. 2006). In cyanobacteria the thylakoid membrane shares the photosynthetic and the respiratory electron pathway. Thus, in dark periods, the PQ-pool is reduced due to respiratory activity. The fast re-reduction kinetics of PSI in cyanobacteria is then caused by the electron supply from $\mathrm{NAD}(\mathrm{P}) \mathrm{H}$. A similar explanation can be assumed for the re-reduction kinetics of PSI in diatoms. From these data it can be concluded that PSI is reduced not only by components of the electron transport chain but also by a mechanism feeding electrons directly into PSI. Ascorbate could be a candidate in serving as an electron donator to PSI, as recently shown in Mano et al. (2004) and Ivanov et al. (2005).

The activity of alternative electron pathways and high stromal reductant pressure have a strong influence on the redox state of $\mathrm{PQ}$, and thus also on redox regulation of gene expression and of the retrograde signalling between chloroplast and nucleus. In view of the recent findings of the missing redox regulation of key enzymes in the Calvin cycle of diatoms (Michels et al. 2005; see also next chapter 6) it can be questioned whether redox control via the PQ-pool is functioning in diatoms in the same way as in Chloroplastida.

\section{Regulation of the enzyme activity in the Calvin cycle in diatoms}

The photosynthetic carbon fixation in plants and algae is based on a eubacterial pathway, the Calvin cycle, which is also found in the prokaryotic ancestors of plastids, the cyanobacteria. Surprisingly only some of the Calvin cycle enzymes in Chloroplastida are of cyanobacterial origin, while others have been replaced by protobacterial or eukaryotic enzymes (Martin et al. 2000). Differentially substituted enzymes can even be found between different algal clades. For instance diatoms contain a Class II fructose-1,6-bisphosphate aldolase (FBA), while in plastids of Chloroplastida only a class I-type isoenzyme is found (Kilian and Kroth 2004). Similarly some of the regulatory properties were adapted from cyanobacteria, while others were newly acquired on the eukaryotic level. Carbon fixation in plastids is not an isolated 
process, but has to be coordinated with various anabolic and metabolic pathways related to carbohydrates and other organic compounds in other compartments and this even in response to external factors. Therefore it is not surprising that Calvin cycle enzymes in Chlorophyta plastids are highly regulated, either by substrates, or by light-dependent redox regulation either on the transcriptional level (Sun et al. 2003; Fey et al. 2005) or at the enzymatical level via the ferredoxin/TR-system (Ruelland and Miginiac-Maslow 1999). In addition to the Calvin cycle (which is also named reductive pentose phosphate pathway) plastids from green algae do possess an oxidative pentose phosphate pathway (OPP), an ubiquitous process that produces NADPH and pentose-phosphates for biosynthesis of nucleotides, amino acids and fatty acids in the dark by decarboxylation of glucose-6-phosphate. As the two pathways are interconnected in plastids, operating them simultaneously would result in a futile cycle, using up energy in the form of ATP without net $\mathrm{CO}_{2}$ fixation. Thus, some of the enzymes of the Calvin cycle (Phosphoribulokinase (PRK), Glyceraldehyde-3-phosphate dehydrogenase (GAP-DH), Fructose-1,6-bisphosphatase (FBPase), and Seduheptulose-1,7-bisphosphatase (SBPase)) are activated in the light via reduction by TR (and in turn are inactive in the dark), while the key enzyme of the OPP, Glucose-6-phosphate dehydrogenase (G6PDH) is active in the dark, but inhibited after reduction in the light. TR is a small protein possessing two cysteyl residues capable of forming an intramolecular disuphide bridge, which can be reversibly reduced in the light by the ferredoxin/TR reductase (FTR) and which is able to reduce target enzymes resulting in altered enzymatic activities (Jacquot et al. 1997). By cross-linking experiments using modified single cysteine TRs various additional potential target enzymes for TR in Chloroplastida and in cyanobacteria have been identified in the recent years (see Hisabori et al. 2005). For diatom plastids, however, it was unclear for a long time as to whether there is any redox control via TR. Just recently a gene for a TR $\mathrm{f}$ was identified on the genome of T. pseudonana (Armbrust et al. 2004). The derived gene product contains the bipartite presequence characteristic for protein targeting into diatom plastids (Kilian and 
Kroth, 2005). Several plastidic enzymes from diatoms have been investigated with respect to regulatory properties, but so far - with one possible exception - all of them are actually not redox-regulated by TR. For PRK it has been shown that in diatoms this enzyme has the potential conserved cysteines for redox regulation. Using strong oxidants it is possible to inactivate the enzyme and to activate it subsequently by addition of TR (Michels et al. 2005). However, due to a shift of the redox midpoint potential of this enzyme it does not get oxidized in vivo and thus is permanently active (Michels et al. 2005). Diatom plastids also possess a different GADPH enzyme compared to plastids of green algae, termed GapC, which does not contain the respective cysteines (Liaud et al. 2000) and which is not affected by oxidation or reduction (Michels et al personel communication). The chloroplast CfoCF1ATP Synthetase in plastids of Chloroplastida is modulated by TR by lowering the energy threshold of the membrane potential that is necessary to activate the enzyme (Ketcham et al. 1984). The sequence cassette containing the respective cysteines is located on the $\gamma$ subunit of the ATPase. The chloroplast ATPase activity in the diatom Odontella sinensis is not affected by reduction (Kroth, personel communication), because like in red algae and in cyanobacteria the $\gamma$ subunits of various diatom enzymes do not possess this sequence cassette (Pancic and Strotmann, 1993) demonstrating that the modulation of the ATPase by TR has been established in the green algal/land plant lineage only. Other plastidic enzymes, which are affected by TR in Chloroplastida, are simply not found in diatom plastids: In green algae there are two malate dehydrogenases, one NAD-dependent enzyme and one NADP-dependent enzyme. The latter enzyme is redox-regulated via TR and serves as a valve for excess NADPH (Scheibe, 2004). From enzymatic analyses and by database search it became obvious that the redox-regulated isoenzyme is missing in diatom plastids (Ocheretina et al. 2000; Mertens and Kroth, personel communication). ADP-glucose pyrophosporylase (AGPase) is used in plastids of Chloroplastida to produce ADP-glucose, the substrate for starch synthesis 
in the light (Geigenberger et al. 2005). Consistent with the fact that diatoms export all carbohydrates immediately from the plastids and store them as chrysolaminarin in cytosolic vacuoles instead, they do not possess a plastidic AGPase. The RubisCO activase, being responsible for activation of the RubisCO (Zhang and Portis 1999), is apparently also missing in diatom plastids as so far no gene for this protein has been found on the T. pseudonana genome. At least there is some evidence that at least one enzyme in diatom plastids redoxregulated in vivo. We found that the FBPase in $O$. sinensis can be activated by the reducing agent dithiothreitol (Michels et al. 2005) with similar activation kinetics as found for spinach FBPase (Hertig and Wolosiuk 1983), however, a clear proof for this still has to be established. As apparently just one enzyme of the Calvin cycle, the FBPase, may potentially be regulated by TR, how do the diatoms manage to regulate oxidative and reductive pentose phosphate pathway separatly? The answer is that diatoms simply do not possess a plastidic OPP. By enzymatic analysis utilizing isolated diatom plastids and by analysis of the genomic database of T. pseudonana it was shown that the key enzymes of the OPP, G6-PDH and 6-PGDH are are missing, while the cytosolic isoenzymes are present (Michels et al.. 2005). It is still unclear how diatoms survive without plastidic oxidative pentose pathway. Peter: please check and see comment 38 and 39: In green algae the OPP is closely connected to the biosynthesis of fatty acids (Jensen, 1985) and to the shikimate pathway (Farr et al., 1994) by supplying NADPH and sugar phosphates in the dark. As diatom plastids do not accumulate starch, sugar phosphates might be imported into the plastids in the dark as well, making an oxidative OPP more or less useless. Reduction equivalents might easily be imported into the plastids by shuttle systems known from land higher plants (Eicks et al. 2002). The OPP might not be the only relocated pathway in diatoms: Liaud et al. (2000) demonstrated that isoforms of the glycolytic enzymes triosephophate isomerase and GAPDH are targeted into the mitochondria. 
Another system regulating the Calvin cycle in Chloroplastida is the formation of protein complexes of GAPDH and PRK together with the small protein CP12 via disulfide bridges (Wedel and Soll 1998). In Chloroplastida these complexes are formed in the dark. In the light and in the presence of NADPH they get reduced by TR, dissociate and release GAPDH and PRK activity (Graciet et al. 2004). A comparison of native GAPDH and PRK enzymes from stromal extracts of diatoms and Chlorophyta by gel filtration revealed that diatoms do not form GAPDH/PRK/CP12 complexes (Michels et al personel communication), accordingly we were not able to identify genes for putative CP12 proteins in diatom genomes.

Taken together redox regulation by TR apparently plays a minor role for the regulation of the Calvin cycle in diatoms. On one hand it is obvious that various regulatory mechanisms related to TR were introduced in the green algal lineage only and therefore are missing in red algae and related secondary algae.. So far it is completely unknown how the Calvin cycle and related processes are regulated. Future work will have to focus on possible changes in the general redox status of the plastids and other signals that might effect the global expression of plastidic enzymes. Futhermore the role of substrates and effectors on the activity individual enzymes will have to be elucidated to understand how diatoms regulate the photosynthetic activity under variable conditions.

\section{Photosrespiration}

RubisCO is the most abundant enzyme in the chloroplast accounting for for up to $30 \%-50 \%$ of its soluble protein. RubisCO fixes inorganic carbon dioxide but through its oxygenase activity is capable of binding molecular oxygen linking C-fixation with photorespiration. Joachim please check and see comments $43,44,45$ : This oxygenase activity of RubisCO is enhanced by high light and high levels of $\mathrm{O}_{2}$ (Beardall 1989). In particular, binding of ribulose 1-5 bisphosphate to $\mathrm{O}_{2}$ results in the formation of 2-P-glycolate and 3- 
phosphoglycerate. Subsequently, glycolate is made available for further metabolism within peroxisomes and mitochondria (Winkler and Stabenau 1994). Alternatively, glycolate can be excreted into the surrounding medium by algae (Parker et al. 2004). Recently an HPLC-based method was used to measure the concentration of the photorespiratory-specific compound glycolate in the culture medium. Exclusively cultures that were shifted from low subsaturating irradiances to the high light intensities released pronounced amounts of glycolate (Schnitzler et al. 2004). Joachim please check and see comment 46: The contribution of photorespiration to the release of dissolved organic carbon from phytoplankton cells has been estimated under laboratory conditions to be about 5\%-10\% (Leboulanger et al. 1998).

In figure 7 the metabolic compartimentation of photorespiratory carbon flow is schematically presented. In diatoms the occurrence of peroxisomes was uncertain for a long time. Neither structures characteristic of these organelles nor the enzyme catalase, which was thought to be a peroxisomal marker, were found in these algae (Winkler and Stabenau 1995). Nevertheless, peroxisomes of diatoms were demonstrated by electron microscopy for the first time in Fragilaria (Winkler and Stabenau 1992). After isolation of these organelles, glycolate dehydrogenase was found to be a constituent of these peroxisomes. This peroxisomal enzyme preferred L-lactate over the D-isomer. In addition, isocitrate lyase and malate synthase activities were detected in the peroxisomal fractions of T. fluviatilis and Nitzschia laevis. Therefore it was suggested that a functional glyoxylate cycle is present in the peroxisomes of these diatoms (Winkler and Stabenau 1995). Joachim: please check comment 47: Sequencing the genome of T. pseudonana resulted in the annotation of a catalase/peroxidase (Armbrust et al. 2004). However, localization of this catalase/peroxidase to peroxisomes could not be predicted. Furthermore, this sequencing effort provided evidence for the presence of a Boxidation pathway in $T$ pseudonana. Potential peroxisomal targeting motifs were found for enzymes known to be specific for B-oxidation of polyunsaturated fatty acids, including a 2,4 dienoyl-CoA reductase and a 4-dienoyl-CoA isomerase. Previously, it was reported that 
enzymes of the fatty acid $B$ oxidation pathway were located in mitochondria exclusively (Winkler and Stabenau 1995). B-oxidation within peroxisomes would generate substantial quantities of $\mathrm{H}_{2} \mathrm{O}_{2}$, which might be detoxified by catalase. In higher plants glycine is produced within the peroxisomes and exported into the mitochondria. No report of glycine production in peroxisomes of diatoms exists up to now.

In addition to peroxisomal glycolate metabolism, glycolate can be directly exported from the chloroplast into the mitochondria of diatoms (Winkler and Stabenau 1995). Inside the mitochondria formation of glycine and serine could be demonstrated by ${ }^{14} \mathrm{C}$ labelling of glycolate (Winkler and Stabenau 1992). A full length sequence of glycine decarboxylase from the centric diatom T. weissflogii was reported recently (Schnitzler and Armbrust 2004). Glycine decarboxylase is a multi-subunit enzyme, comprised of L-, P-, H- and T- proteins. Transcript abundance of this enzyme was demonstrated to be light dependent. In addition, a link between transcript abundance and photorespiratory activity was established (Schnitzler and Armbrust 2004). Export of serine into peroxisomes and subsequent production of glycerate was not observed up to now. Therefore, major differences seem to exist between the photorespiratory pathways of Chloroplastida and diatoms. Furthermore, evidence was presented that $\mathrm{C} 4$ photosynthesis supports carbon assimilation in the marine diatom $T$. weisflogii (see also next chapter 8) (Reinfelder et al. 2000; Falciatore and Bowler 2002; Giordano et al. 2005). Moreover, a number of intriguing differences were identified between the pennate and the centric diatoms concerning activities of relevance for general cell metabolism, e.g. genes involved in carbon-concentrating mechanisms, cytosolic acetylCoenzyme A production etc. (Maheswari et al. 2005; Monisant et al. 2005). Details of the specific properties of the photorespiratory pathway in diatoms will be further analyzed by metabolite profiling and construction of linkage networks. 


\section{Carbon acquisition in diatoms}

In spite of high concentrations of dissolved inorganic carbon in most aquatic environments, phytoplankton has to invest considerable resources in carbon acquisition to allow high rates of photosynthesis. The reason for this is RubisCO relies on $\mathrm{CO}_{2}$ as the only carbon substrate and is characterized by a low substrate affinity and a slow maximum specific turnover rate. With $\mathrm{CO}_{2}$ half-saturation constants ranging between 30 and $40 \mu \mathrm{mol} \mathrm{l}^{-1}$ (Badger et al. 1998), $\mathrm{CO}_{2}$ affinity of diatom RubisCO is among the highest of all phytoplankton taxonomic groups (Tortell 2000). Still, at typical seawater $\mathrm{CO}_{2}$ concentrations, ranging between 10 and $25 \mu \mathrm{mol}$ $1^{-1}$, RubisCO carboxylation is well below saturation. To overcome the 'imperfection' of their main carboxylating enzyme, diatoms, like most most microalgae, have developed energydependent mechanisms, which increase the $\mathrm{CO}_{2}$ concentration at the site of carboxylation, the so-called $\mathrm{CO}_{2}$ concentrating mechanisms (CCM). These include active uptake of $\mathrm{CO}_{2}$ and $\mathrm{HCO}_{3}{ }^{-}$into the algal cell and/or into the chloroplasts, the conversion between $\mathrm{HCO}_{3}{ }^{-}$and $\mathrm{CO}_{2}$ intra- and extracellularly with the enzyme carbonic anhydrase $(\mathrm{CA})$ and $\mathrm{CO}_{2}$ accumulation via $\mathrm{C}_{4}$ and CAM pathways (forreview see Giordano et al. 2005).

Recent studies indicate that large differences exist in both the efficiency and regulation of the CCM between phytoplankton taxonomic groups. Whereas some species preferably use $\mathrm{CO}_{2}$ as a carbon source, others mainly draw their inorganic carbon from the large pool of $\mathrm{HCO}_{3}{ }^{-}$(e.g. Korb et al. 1997; Elzenga et al. 2000). Photosynthetic carbon fixation rate of all diatom species tested so far are at or close to $\mathrm{CO}_{2}$-saturation at present day $\mathrm{CO}_{2}$ levels (Burkhardt et al. 1999; 2001; Rost et al. 2003). In contrast, the coccolithophorids Emiliania huxleyi and Gephyrocapsa oceanica are well below saturation at these levels (Riebesell et al. 2000; Rost et al. 2003) due to low affinities in the inorganic carbon uptake systems and low extracellular carbonic anhydrase (CA) activities. Large differences are also observed with regard to CCM 
regulation (Burkhardt et al. 2001; Rost et al. 2003). Highly regulated carbon acquisition in the diatom S. costatum can be ascribed to increasing affinities in the $\mathrm{CO}_{2}$ and $\mathrm{HCO}_{3}{ }^{-}$uptake systems, an increasing contribution of $\mathrm{HCO}_{3}{ }^{-}$to the overall carbon acquisition and an increase in $\mathrm{CA}$ activity with decreasing $\mathrm{pCO}_{2}$. In contrast, the prymnesiophyte Phaeocystis globosa showed a rather constitutive carbon acquisition, which was reflected in a constant contribution of $\mathrm{HCO}_{3}{ }^{-}$to the overall carbon acquisition and high extracellular CA activities independent of the $\mathrm{pCO}_{2}$.

Considering the high concentrations of $\mathrm{HCO}_{3}{ }^{-}$(approx. $1800 \mu \mathrm{mol} \mathrm{l^{-1 }}$ ) relative to $\mathrm{CO}_{2}(10$ to $25 \mu \mathrm{mol} 1^{-1}$ ) in seawater and the ability for active $\mathrm{HCO}_{3}{ }^{-}$uptake in diatom species tested so far raises the question, why marine diatoms do not rely on the abundant $\mathrm{HCO}_{3}{ }^{-}$pool in seawater as the sole inorganic carbon source. The coexistence of both $\mathrm{CO}_{2}$ and $\mathrm{HCO}_{3}{ }^{-}$transport systems with preference for $\mathrm{CO}_{2}$ uptake at higher $\mathrm{CO}_{2}$ concentrations may be maintained for energetic reasons. Owing to the negative charge of $\mathrm{HCO}_{3}{ }^{-}$and the inside-negative electric potential difference across the plasmalemma, the energetic costs of $\mathrm{HCO}_{3}{ }^{-}$uptake was suggested to be higher than that of $\mathrm{CO}_{2}$ uptake (Burkhardt et al. 2001). However, considering that for each $\mathrm{HCO}_{3}{ }^{-}$entering the cell and being fixed as $\mathrm{CO}_{2}$ one $\mathrm{H}^{+}$has to enter or $1 \mathrm{OH}^{-}$to leave the cell in order to maintain intracellular $\mathrm{pH}$ balance, the energetic cost for $\mathrm{HCO}_{3}{ }^{-}$ uptake may turn out similar to that of active $\mathrm{CO}_{2}$ transport. As argued by Granum et al. (2005), this holds true in the case that $\mathrm{HCO}_{3}{ }^{-}$uptake occurs via a $\mathrm{H}^{+}: \mathrm{HCO}_{3}{ }^{-}$symporter or a $\mathrm{OH}^{-}: \mathrm{HCO}_{3}{ }^{-}$antiporter, which have the same minimum energy cost per mole of carbon uptake as for an ATP-powered $\mathrm{CO}_{2}$ transporter. Whatever the advantage for the coexistence of $\mathrm{CO}_{2}$ and $\mathrm{HCO}_{3}{ }^{-}$transport systems may be, the fact that diatoms frequently thrive and are highly competitive under light (energy) limiting conditions suggest that the key to answering this question is likely to be founded on energetic reasons. 
In addition to the biophysical mechanisms for $\mathrm{CO}_{2}$ accumulation discussed above, recent work has indicated the operation of a biochemical mechanism via a $\mathrm{C}_{4}$ pathway in the marine diatom T. weissflogii (Reinfelder et al. 2000; 2004). Short-term labelling of $\mathrm{C}_{4}$ compounds and transfer of carbon to PGA was demonstrated in cells grown under inorganic C-limited conditions. Use of a PEPCase inhibitor resulted in a $90 \%$ decrease in photosynthesis in $T$. weissflogii acclimated to low $\mathrm{CO}_{2}$, but had little effect under high $\mathrm{CO}_{2}$ or low $\mathrm{O}_{2}$ conditions (Reinfelder et al. 2004). In contrast, no such effect of the inhibitor was observed in the chlorophyte Chlamydomonas sp. Addition of oxalacetic acid, the $\mathrm{C}_{4}$ product of PEPCase, suppressed the fixation of inorganic carbon fixation in $T$. weissflogii. This effect was strongest in cells grown under low $\mathrm{CO}_{2}$ conditions, suggesting regulation of the $\mathrm{C}_{4}$ pathway in response to $\mathrm{CO}_{2}$ availability (Reinfelder et al. 2004).

The recent sequencing of the genome of T. pseudonana (Armbrust et al. 2004) has revealed the presence of genes coding for enzymes necessary in $\mathrm{C}_{4}$ photosynthesis, such as PEPCase, PEPCKase, and PPDK, which catalyzes the synthesis of PEP in many C4 plants. The cellular localisation of these enzymes in diatoms, a critical factor in determining their involvement in $\mathrm{C}_{4}$ photosynthesis, however, is uncertain. To allow for simultaneous carbon fixation by PEPCase and RubisCO in a single cell would require intracellular compartmentalisation (Riebesell 2000). In view of these uncertainties the evidence for the operation of C4 photosynthesis in diatoms is still considered incomplete (Giordano et al. 2005). While a C4 pathway in diatoms seems redundant with the observed active uptake of $\mathrm{CO}_{2}$ and $\mathrm{HCO}_{3}{ }^{-}$, both the biophysical and biochemical mechanisms may be integral components of the highly efficient and tightly regulated $\mathrm{CO}_{2}$ concentrating mechanism in diatoms.

side from $\mathrm{CO}_{2}$ availability, other environmental factors such as supply of macro- and micronutrients, photon flux density, UV radiation and temperature, can modulate CCM activity (see review by Beardall and Giordano 2002). Surprisingly little information is 
available on diatom CCM modulation by these ecologically relevant factors. The need for a better understanding of these aspects becomes obvious in view of the present and projected future changes in environmental conditions. Global warming will raise surface water temperatures, increase surface layer stratification and decrease deep water ventilation. This will lower the supply of inorganic nutrients from deeper layers and will increase mean photon flux densities in the upper mixed layer. The capacity of CCM regulation in response to these changes may play an important role in determining the ecological fitness of individual phytoplankton species and taxonomic groups under future conditions.

Recent important advances in the T. pseudonana genome project (Armbrust et al. 2004) in combination with improved technology to characterise and quantify CCM activity and regulation on the cellular and molecular level will help to unravel mechanisms, regulation and environmental modulation of diatom carbon acquisition. A better understanding of these processes will be a prerequisite to further elucidate the role of carbon acquisition in an ecological and evolutionary context and may help to improve our predictive capability of possible changes in plankton composition and succession.

\section{Synthesis and breakdown of storage products under starvation.}

\section{Storage products}

Under nutrient replete conditions diatoms primarily accumulate the $\beta$-1,3-D-glucan chrysolaminarin (Granum et. al. 2002) as a storage product. This is a water-soluble polysaccharide, localized in vacuoles. It can be metabolized rapidly during dark periods, and therefore serves as a respiratory substrate. Both, an endo- and exo-1,3- $\beta$-glucanase were identified on genome level (Armbrust et al. 2004). 
All plastid-containing organisms examined so far carry out de novo biosynthesis of fatty acids within the plastid via the type II fatty acyl synthase (Waller et. al. 1998). Diatoms can contain large proportions of polyunsaturated fatty acids. Armbrust et al (2004) identified a complete pathway for polyunsaturated fatty acid biosynthesis. After export from the plastid, lipid or oildroplets often accumulate in the vacuoles or in cytoplasm under nutrient-limited conditions. Furthermore, Armbrust et al (2004) reported the identification of enzymes necessary for a complete urea cycle in $T$. pseudonana which is in contrast to Chloroplastida . Evidence was found, that in T. pseudonana the energy storage product creatine phosphate is generated from a branch pathway of the urea cycle.

\section{Metabolic reaction to nutrient stress}

In response to nutrient limitation diatoms, like other phytoplankton cells, undergo metabolic acclimatization, which often results in changes of the cellular composition of macromolecules. Nitrogen or phosphate limitation reduces the ability to use photosynthetically fixed carbon for protein synthesis, but does not prevent the formation of photosynthetic storage products (Berges et. al. 1996; Granum and Myklestad 2002). Consequently, a gradual increase in cellular carbon reserves without a concomitant increase in organic nitrogen (expressed as increased $\mathrm{C} / \mathrm{N}$ ratio) as well as decline of $\mathrm{Chl}$ a and of photochemical efficiency are observable (Shifrin and Chisholm 1981, Berges and Falkowski 1998, Lippemeier et. al 2001). Berges and Falkowski (1998) showed that N-starvation affected the maximum quantum yield of PS II of the diatom $T$. weissflogii more severe than of the chlorophyceae Dunaliella tertiolecta. It is known that diatoms tend to dominate phytoplankton under high-nutrient concentrations. Sarthou et al (2005) summarized halfsaturation values of marine diatoms which have a wide range of variation indicating that generally these are above the annual sea surface concentrations (Levitus et al. 1993). The need of nutrient-rich conditions for growth could also originate from large cell size, causing 
relatively low surface to volume ratios of diatoms, which limit an efficient exploitation of low nutrient concentrations. The range of variation of cell size of diatoms comprises more than one order of magnitude $\left(13-7 * 10^{5} \mu \mathrm{m}^{3}\right.$, Sarthou et. al, 2005). These might be some reasons for the strong effect of nitrogen starvation on T. weissflogii (cell volume: $1362 \mu \mathrm{m}^{3}$ ) in contrast to D. tertiolecta (cell volume: $391 \mu \mathrm{m}^{3}$; Atkinson et. al 2003 and references therein) as it was reported from Berges and Falkowski (1998). However, it is also known that diatoms can adapt to low nutrient concentrations by reducing their size (Sarthou et. al. 2005).

Under N-limited conditions a simultaneous accumulation of glucan and lipids was found in $S$. costatum (Granum et. al 2002). Guerrini et al (2000) showed an accumulation of cellular carbohydrates in Achnanthes brevipes under both, nitrogen- and phosphate-depleted conditions. The authors conclude that increased polysaccharide reserves accumulated under $\mathrm{N}$-limitation represent carbon skeletons that will be used for protein synthesis when nitrogen is available again. Glucan accumulation under phosphate depletion seems to be a result of decreased catabolism.

Nutrient starvation also induces/increases the extrusion of extracellular polymeric substances (EPS), primarily polysaccharides in benthic and marine diatoms (Guerrini et al. 2000, Granum et.al. 2002, Underwood et al. 2004) independent of photorespiratory conditions. The excretion seems to be a response to unbalanced growth where the amount of fixed carbon exceeds the capacity of carbon storage within the cell. The composition of extracellular carbohydrates varies in dependence on the nutrient status of the cell and environmental conditions. Underwood et al. (2004) identified two EPS types (EPS type 1 and 2) in Cylindrotheca closterium, which were produced under nutrient limiting and non-limiting conditions. Nutrient-replete cells produced a complex EPS containing rhamnose, fucose, xylose, mannose, galactose, glucose, and uronic acids. Nutrient-limited cells produced an additional EPS containing mannose, galactose, glucose, and uronic acids. In A. brevipes the amount of released polysaccharides was found to be higher under phosphate depletion (Guerrini et al. 
2000), whereas nitrogen depletion induced a higher accumulation of intracellular carbohydrates. Granum et al. (2002) reported the release of organic carbon, comprising monosaccharides, polysaccharides and free amino acids in S. costatum.

Carbohydrate release was also shown for the cyanobacterium Synechocystis aquatilis $f$. salina (Nascimento et al. 1999) under nutrient deprivation. Nitrogen starvation caused a high initial carbohydrate release, because this photosynthetic product could not serve as carbon skeleton source in protein synthesis. The authors conclude that the release was a consequence of high intracellular carbohydrate concentrations. By contrast, the excretion of polymeric carbohydrates in green algae in response to stress is not known.

Another major limiting nutrient of diatom growth is silicon. Cellular energy for silicification and transport originates from aerobic respiration without any direct involvement of photosynthetic energy (Martin-Jézéquel et al. 2000). As such, diatom silicon metabolism differs from that of other major limiting nutrients such as nitrogen and phosphorous, which are closely linked to photosynthetic metabolisms (Claquin et al 2002). Cell wall silicification and silicic acid transport are tightly coupled to the cell cycle, which results in a dependency in the extent of silicification on growth rate. Under silicon limiting conditions Roessler (1988) showed an increased accumulation of lipids in C. cryptica. This accumulation appears to be due to two distinct processes: an increase in the proportion of newly assimilated carbon partitioned into lipids, and a slow conversion of previously assimilated carbon form non-lipid compound into lipids.

\section{Metabolization of storage products in darkness}

In the natural environment, nutrient elimination from the euphotic zone to the sediment is driven to an important extent by sinking of autotrophic cells, especially by diatoms. During sedimentation of the cells metabolic processes are still active leading to changes in biomass composition. Berges and Falkowski (1998) showed that cell numbers, pigment ratios, and 
photosynthetic capacity of $T$. weissflogii remained constant during two weeks of darkness. Similar results were obtained for five polar diatom species surviving up to 214 days dark incubation and were able to grow when reexposed to light (Peters and Thomas 1996). After an initial decline, mainly due to a loss of carbon, $\mathrm{C} / \mathrm{N}$ ratios also remained more or less unchanged (Berges and Falkowski 1998; Peters and Thomas 1996). This is in agreement with the quantitative decline of carbohydrates and lipids on a per cell level of $C$. meneghiana measured with FTIR spectroscopy (Stehfest et al. 2005). The breakdown of storage products in C. meneghiniana due to 34 days of darkness caused a decline of all cellular macromolecules with time. The data showed that the storage products are decreased for energy supply in a well defined sequence: Lipids showed the fastest decrease, followed by carbohydrates, whereas protein declined very slowly. Diatoms have the capability to assimilate nitrate in the dark. $\mathrm{N}$-assimilation is induced by high light intensities or $\mathrm{N}$ limitation when $\mathrm{N}$-assimilation or $\mathrm{N}$-transport could not keep up with carbon fixation (Clark et al., 2002). Vårum and Myklestad (1984) reported an increased mobilization of chrysolaminarin in the dark and suggest that the polysaccharide is used for delivering carbonskeletons for the biosynthesis of amino acids.

Although the survival of prolonged periods of darkness for Scenedesmus quadricauda was reported (Furusato et. al, 2004), no data are available concerning the survival of green algae in darkness for several months. Diatoms have the capability to withstand long periods of darkness and restart growth rapidly upon return to light. The reasons are not understood in detail, but one explanation might be that diatoms have the capability to maintain their photosynthetic performance (Peters and Thomas 1996; Murphy and Cowles 1997; Furusato et al. 2004) using chlororespiration to protect cells from photodamage after return to light (Jakob et al. 1999) . Another beneficial factor might be the high accumulation of lipids. This longterm storage product of reduced carbon has the additional advantage of enhancing buoyancy. 
Lipid degradation seems to be related to other physiological functions e.g. to $\beta$-oxidation of fatty acids (see chapter 6)

\section{Elemental composition and nutrient uptake in diatoms (zuarbeit fehlt noch daher noch nicht überarbeitet)}

Microalgae and plants require essential macro- and micronutrients for growth. In photoautotrophs, the macronutrients nitrogen and phosphorus are used in anabolic reaction as a sink for the photosynthetically fixed organic carbon and to provide the building blocks for all other cellular components. While the bulk of the assimilated nitrogen is used for protein and nucleic acid biosynthesis, phosphorus is a major component only in nucleic acid and phospholipids (reviewed in Geider and LaRoche, 2002). Recent work on the elemental stoichiometry of phytoplankton has revealed some significant differences between the green and the red plastid lineages. On average, the N:P ratio of marine chlorophytes was higher $(\mathrm{N}: \mathrm{P} \sim 25)$ then that of diatoms $(\mathrm{N}: \mathrm{P} \sim 10)$ grown under the same conditions (Quigg et al. 2003). Experimental evidence suggest that the difference in $\mathrm{N}: \mathrm{P}$ between organisms is due largely to variations in the partitioning between total cellular proteins and rRNA, although the $\mathrm{N}: \mathrm{P}$ ratio will also be influenced by variation in the $\mathrm{N}$ - and $\mathrm{P}$-storage ability of the various algal groups (Geider and LaRoche, 2002).

The difference in stoichiometry of micronutrients between the green and red plastid lineages is even more striking, and a link between the timing of the evolution and the trace metal composition of the plastid lineages has been hypothesized (Quigg et al. 2003, Falkowski et al 2004). The green plastid lineage appears to have inherently higher cellular quotas of iron, zinc and copper relative to those of red algae and secondary red plastid symbionts. In contrast, the red plastid lineages are characterized by higher cellular quotas for manganese, cobalt and cadmium (Quigg et al 2003). Julie please check comment 68: The 
composition of metals reflects the plastid rather then the host lineage and one can hypothesize that the trace metal preferences will reflect true differences in the metabolism of the organisms, especially with respect to the photosynthetic machinery. A novel type of carbonic anhydrase, containing $\mathrm{Cd}$ rather then $\mathrm{Zn}$, has been recently discovered in a marine diatom (Lane et al. 2005) confirming a biological role for this element and explaining the nutrientlike profile of $\mathrm{Cd}$ in the oceans. This discovery supports the hypothesis that, in diatoms, metals such as $\mathrm{Cd}, \mathrm{Mn}$, and Co may provide alternatives to the more commonly found $\mathrm{Fe}$-, Zn- and Cu-based enzymes (Quigg et al. 2003).

Julie: please check comment 69: One unique aspect of diatoms among extant photoautotrophic organism is their silicon requirement. The ability to precipitate silicic acid into an exquisitely patterned silica cell wall has been studied in part because of its potential importance to the developing field of nanotechnology (Kröger et al 2003). Silaffins and silicic acid transporters (SIT), two biochemical components involved in frustule formation have been so far uniquely found in diatoms (Hildebrand et al. 1998, Kröger et al. 2002). In the modern ocean, diatoms play an important role in the silicon biogeochemical cycle, and diatom growth is often limited by dissolved silica concentrations (Falkowski et al. 2004). The ecological significance of the silica cell wall remains unclear, but many hypotheses exist, ranging from a lower energetic cost then organic carbon based cell wall (Raven, 1983) to mechanical protection (Hamm et al 2003).

Although diatoms can survive under low nutrient conditions, they are also well adapted to rapidly take up nutrients at elevated concentrations (Collos et al 2005). This suggests that both high affinity and low affinity nutrient transporters are present in diatoms. A compilation of nutrient uptake kinetic parameters from experimental work with diatoms demonstrates a large interspecific variability in addition to the environmentally caused acclimation response within single species (Sarthou et al. 2005). The compiled data yielded mean half saturation constants $(\mathrm{Ks})$ for $\mathrm{NO}_{3}, \mathrm{PO}_{4}, \mathrm{Si}$ (Table 1) of 1.6, 0.24, $3.9 \mu \mathrm{M}$, 
respectively and a range for each nutrient that spanned several orders of magnitude. Julie please check comment 70In contrast, the average reported $\mathrm{K} \mu$ for Fe uptake (Ks for Fe are seldom measured) was $0.35 \mathrm{nM}$, more then 3 orders of magnitude lower then $\mathrm{Ks}$ for macronutrients.

An analysis of the genome of $T$. pseudonana suggests that diatoms can assimilate nitrogen from ammonium, nitrate, nitrite, urea, amino acids and purines (Armbrust et al. 2004). Although the enzymes for purine utilization (e.g. Allantoicase, http://genome.jgipsf.org/chlre2/chlre2.home.html) are not found in the Chlamydomonas genome, most other nitrogen sources can be utilized by diatoms and chlorophytes alike. Julie please check comment 71 Ammonium is the most energetically efficient source of nitrogen and is preferentially assimilated by algae. In most organisms, transport of ammonium ions across membranes is carried out by members of the ammonium transporter family (AMT), a group of evolutionary-related proteins found in bacteria, yeast, algae and higher plants. Several ammonium transporters all belonging to the AMT family have been identified in diatoms (Hildebrand 2005, Allen 2005). Two groups of ammonium transporter, AMT1 and AMT2 found in $C$. fusiformis are not only upregulated by nitrogen limitation but are also expressed at a higher level when grown on nitrate compared to ammonium (Hildebrand 2005). The utilization of nitrate requires the presence of nitrate transporters, as well as nitrate reductase and nitrite reductase. The T. pseudonana genome contains multiple genes for nitrate transporters as well as the other enzymes essential for nitrate assimilation. All eukaryotic nitrate reductases are well conserved in the major functional domains and this is also the case for the diatom enzymes (Allen et al. 2005). However, the homology to other NR is generally less then $30 \%$ in the less conserved regions. The nitrate reductase of diatoms exhibits a low temperature optimum and this feature may reflect structural differences in the $\mathrm{N}$-terminal of the enzyme itself (Berges et al 2002). The specific structure of the nitrate reductase may be a 
key selective advantage for diatoms, allowing them to utilize the high nitrate concentrations characteristic of turbulent water regimes and to bloom at cold temperatures.

In Chlamydomona the specific response to phosphate limitation is characterized by the synthesis of a high-affinity Pi uptake system and the secretion of PHOX alkaline phosphatase (Chang et al. 2005). The genomes of both Chlamydomonas and T. pseudonana contain members of a phosphate transporter family related to $\mathrm{PHO}-4$, a $\mathrm{Na}(+)$-phosphate symporter from yeast (Chang et al. 2005, http://genome.jgi-psf.org/thaps1), and in Chlamydomonas, the high affinity phosphate transporter PTB2, expressed only under P-limitation, belongs to this protein family. However, the alkaline phosphatases found in T. pseudonana have no homology to PHOX, the Chlamydomonas enzyme.

All living organisms have evolved biochemical systems for iron acquisition and cellular homeostasis. Diverse strategies have evolved in closely related species, and one can expect this diversity to be also present in diatoms. Diatoms can survive and grow at iron concentrations of only a few nM, even in laboratory cultures (Sunda et al 1997). In constrast, Chlamydomonas shows signs of severe iron limitation when grown with $100 \mathrm{nM} \mathrm{Fe}$ (Lafontaine et al. 2002). Very little is known about the biochemical nature of the diatom's high affinity iron uptake systems. The T. pseudonana genome has revealed the presence of at least two ferric reductases, a multicopper oxidase and two iron permeases (Armbrust et al. 2004) but, based on amino acid sequence homology, these are only distantly related to the high affinity iron-uptake system of Chlamydomonas (Lafontaine et al. 2002) and yeast (Rutherford and Bird, 2004). The T. pseudonana genome also contains genes that might be involved in siderophore synthesis.

The overwhelming success of diatoms in the iron-poor marine environment, at least relative to the green algae (Falkowski et al 2004), may in fact stem from their ability to reduce their cellular iron quota. In phototrophs, most of the iron requirements are within the photosynthetic apparatus, and under iron limitation, the photosynthetic architecture is 
remodeled to reduce iron requirements and protect against excessive light absorption (Moseley et al 2002). In contrast to Chlamydomonas and cyanobacteria, where PSI is at least as abundant as PSII, PSI/PSII is usually less then 1 in diatoms and can be further reduced in iron-limited cells (Strepeck and Harrison, 2004). Since PSI contains 12 iron atoms in contrast with 3 in PSII, a reduction in PSI will contribute significantly to decreasing the iron requirements in diatoms. Julie please check comment 73 Diatoms also have the ability to replace iron-containing proteins such as ferredoxin by flavodoxin, and Fe-superoxide dismutase for Mn superoxide dismutase (LaRoche et al. 1999) resulting in additional savings in Fe. The ability to replace ferredoxin by flavodoxin appears common in diatoms (LaRoche et al. 1999). Although flavodoxin is present in Chlorella and D. tertiolecta proteins with an alternate protein that does not contain iron is not specific to diatoms. Although all diatoms appear to contain flavodoxin, the gene encoding flavodoxin is absent in the Chlamydomonas and higher plant genomes, but is present in some green algal species, notably D. tertiolecta (LaRoche et al.1999).

\section{Diatoms as extremophiles}

Diatoms can life in quite extreme enviroments, e.g. intertidal areas where they have to tolerate extreme changes in radiation and salinity or water films, e.g. on rocks or trees. However, in most of these habitats other taxa, including green algae, are as successful as diatoms. E.g. the green alga Chlorella nivalis can survive at low temperatures on snow (Kawecka and Drake 1978). There is, however, an extreme cold ecosystem where diatoms seemingly are most competitive and outnumber other taxa, sea ice. It might be hypothezied that the ecological success of diatoms in this environment is due to the metabolic peculiarites listed above. Sea ice, other than freshwater ice, is not a solid matrix, but contains a system of fine channels filled with brine originating from the expulsion of ions from seawater during the 
freezing process, which can be heavily populated by diatoms (Gleitz et al. 1998). Therefore, the shells of sea ice diatoms are used as a paleoproxy for sea ice coverage of the Polar Seas (Leventer 1998). Presently at any given time sea ice covers more than 13 Mio $\mathrm{km}^{2}$ and as such is a huge ecosystem. Conditions in this environment are extreme with respect to temperature (between -2 and $-40^{\circ} \mathrm{C}$ ), salinity (between 30 and $150 \mathrm{PSU}$ ) and radiation as well as high $\mathrm{pH}$ values (up to $\mathrm{pH} 10$ ). Due to high cell densities photosynthetic activity can as high that the oxygen saturation exceeds several $100 \%$. Therefore, it is usually not only a single stressor at a time, but a combination of several. Through the freezing process the salinity in the brine increases dramatically which asks for an energy dependent maintenance of an internal osmotic value suitable for survival and photosynthesis. The thick ice layer above the cell can reduce irradiance to values as low as $<0.1 \%$ of solar radiation at sea level. Therefore, photosynthetic cells have to adapt to extremely low light intensities. Since the gas exchange between the brine and the open water or the atmosphere is rather limited, photosynthetic activity in the brine leads to the depletion of dissolved inorganic carbon (DIC), shifting the $\mathrm{pH}$ to values up to 10 and higher, and to hyperoxic conditions, that facilitate the production of reactive oxygen species (ROS) (Thomas and Dieckmann 2002). Therefore, the metabolic costs are increased by efficient ROS scavenging and carbon pumping by CCM. Finally, the air temperature above sea ice can be as low as $-40^{\circ} \mathrm{C}$, while the temperature of the underlying seawater is usually around the freezing point of seawater $\left(-1.8^{\circ} \mathrm{C}\right)$, resulting in strong temperature gradients, which asks for special adaptations in the lipid and protein compostion in the membranes.

Under these extreme environmental conditions a low primary production within sea ice would be expected. However, the productivity is higher compared to the open water and chlorophyll concentration may exceed that in open water by a factor of 1000 (Thomas and Dieckmann 2002). During the ice melt in spring and early summer, sea ice populations can serve as a "seed population" for the water column, emphasizing their ecological importance in 
Polar seas. Interestingly, dominating diatoms in sea ice can also thrive in melting ponds and remain dominant in the pelagic community, e.g. the genus Fragilariopsis which was ubiquitously found in phytoplankton counts (Halldal 1953; Paasche 1960; Quillfeld 1997). This implies that these diatoms are not restricted to an extreme environment like most other extremophiles, but can successfully compete with other taxa under totally different condtions. Therefore, their metabolic flexibility is able to acclimate to an extreme wide range of environmental conditions.

We are just beginning to understand the physiological basis of this extremophily. Laboratory studies showed that polar diatoms (e.g. Fragilariopsis curta, Navicula gelida var. antarctica, Nitzschia medioconstricta) contain high levels of polyunsaturated fatty acids, which may help to maintain membrane fluidity at low temperatures. Preliminary data suggest that they react to changes in temperature by changing their fatty acid profiles (Mock and Kroon 2002; Lange, personel communication.) similar to that known from cyanobacteria (Los and Murata 2004) andby the production of "ice-active substances" (Raymond and Knight 2003). Under low temperatures already moderate light intensities (i.e. $35 \mu \mathrm{Em}^{-2} \mathrm{sec}^{-1}$ ) lead to an unbalance between absorption and $\mathrm{CO}_{2}$ assimilation capacity resulting in significant changes in the expression of photosynthetic genes e.g. ftsH, psbA, fcp (Mock and Valentin 2004). EST libraries established under low temperature, high salinity and low light contained genes for unusual fucoxanthin chlorophyll binding proteins $(f c p)$, antifreeze proteins and many stress related proteins (Mock and Valentin 2004; Mock et al. 2005). The application of chip technologies will deliver more data on stress related gene expression in these extremophilic organism leading to a better understanding of the physiological basis of such an extreme environmental adaptation capacity. 


\section{Conclusions}

The understanding of the metabolic differences between diatoms and green algae is not only important for basic research but also for applied reasons. For instance several models for the assessment of the primary production in a given environment have been developed on the basis of the assumption that the electrons liberated from PS II will be used for biomass formation in a rather taxon-independent manner. However, it was recently shown by Wagner et al. (2006) that in diatoms the alternative electron cycling is significantly lower than in green algae, especially under the conditions of fluctuating light conditions close to the situation in true nature. This higher efficiency in biomass formation may be related to many processes: reduced costs for pigment biosynthesis, for photoprotection, prevention of photorespiratory losses etc. The fact that these basic processes are mechanistically not uniform in all phototrophs is a new challenge for the post-genome research. 


\begin{tabular}{|c|c|c|c|}
\hline \multicolumn{2}{|r|}{ Enzyme Name } & \multirow{2}{*}{$\begin{array}{c}\text { Gene }^{1} \text { in } \\
\text { T. pseudonana }\end{array}$} & \multirow{2}{*}{$\begin{array}{c}\text { Gene } \\
\text { Model }^{2}\end{array}$} \\
\hline & & & \\
\hline 1 & glutamyl-tRNA synthetase & GTS & newV2.0.genewise.91.91.1 \\
\hline 2 & glutamyl-tRNA reductase & GTR & newV2.0.grail.31.102.1 \\
\hline 3 & glutamate-1-semialdehyde aminotransferase & $G S A$ & newV2.0.genewise.6.14.1 \\
\hline 4 & 5-aminolevulinic acid dehydratase & $A L A D$ & newV2.0.genewise.38.321.1 \\
\hline 5 & porphobilinogen deaminase & $P B G D$ & newV2.0.genewise.37.9.1 \\
\hline 6 & uroporphyrinogen III synthase & UROS & newV2.0.genewise.159.2.1 \\
\hline \multirow[t]{3}{*}{7} & uroporphyrinogen III decarboxylase & URODI & newV2.0.genewise.20.4.1 \\
\hline & & UROD2 & newV2.0.genewise.8.981.1 \\
\hline & & UROD3 & see Lohr et al., 2005 \\
\hline \multirow{2}{*}{8} & coproporphyrinogen III oxidase & CPXI & newV2.0.genewise.69.87.1 \\
\hline & & $C P X 2$ & newV2.0.grail.67.2.1 \\
\hline 9 & protoporphyrinogen IX oxidase & $P P X$ & newV2.0.genewise.64.58.1 \\
\hline \multirow[t]{4}{*}{10} & protoporphyrin IX Mg-chelatase subunit D & CHLD & newV2.0.genewise.15.180.1 \\
\hline & protoporphyrin IX Mg-chelatase subunit $\mathrm{H}$ & CHLHI & newV2.0.genewise.28.59.1 \\
\hline & & $\mathrm{CHLH} 2$ & newV2.0.genewise.51.106.1 \\
\hline & protoporphyrin IX Mg-chelatase subunit I & CHLI & encoded on plastid genome \\
\hline 11 & $\mathrm{Mg}$-protoporphyrin IX methyltransferase & $P P M T$ & newV2.0.genewise.221.3.1 \\
\hline 12 & Mg-protoporphyrin IX monomethylester cyclase subunit 1 & CHL27 & no homolog detectable \\
\hline \multirow[t]{2}{*}{13} & divinylprotochlorophyllide reductase & $D C R 1$ & newV2.0.grail.19.47.1 \\
\hline & & $D C R 2$ & newV2.0.grail.16.48.1 \\
\hline \multirow[t]{2}{*}{14} & light-dependent NADPH:protochlorophyllide oxidoreductase & PORI & newV2.0.genewise.17.695.1 \\
\hline & & POR2 & newV2.0.grail.34.35.1 \\
\hline 15 & chlorophyll synthase & CHS & newV2.0.grail.1.376.1 \\
\hline 16 & geranylgeranyl reductase & $G G R$ & newV2.0.genewise.45.144.1 \\
\hline 21 & 1-deoxy-D-xylulose-5-phosphate synthase & $D X S$ & newV2.0.grail.6.114.1 \\
\hline 22 & 1-deoxy-D-xylulose-5-phosphate reductoisomerase & $D X R$ & newV2.0.genewise.200.8.1 \\
\hline 23 & 4-diphosphocytidyl-2-C-methyl-D-erythritol synthase & $C M S$ & newV2.0.genewise.25.439.1 \\
\hline 24 & 4-diphosphocytidyl-2-C-methyl-D-erythritol kinase & $C M K$ & newV2.0.genewise.20.382.1 \\
\hline
\end{tabular}


(newV2.0.genewise.584.6.1)

25 2-C-methyl-D-erythritol 2,4-cyclodiphosphate synthase

26 1-hydroxy-2-methyl-2-(E)-butenyl-4-diphosphate synthase

27 isopentenyl- / dimethylallyl-diphosphate synthase

28 isopentenyl diphosphate isomerase

29 geranylgeranyl pyrophosphate synthase

30 phytoene synthase

31 phytoene desaturase

$32 \zeta$-carotene desaturase

33 carotenoid isomerase

34 lycopene $\beta$-cyclase

35 carotene $\beta$-hydoxylase

36 zeaxanthin / diatoxanthin epoxidase
$M C S$

$H D S$
$L C Y B$

CHYB

$I D S$

IDI1 (cytosol?)

IDI2 (plastid?)

GGPPS

PSY1

PSY2

PDS1

PDS2

$Z D S$

CIS

ZEP1 (DEP1)

ZEP2 (DEP2)
newV2.0.genewise.432.1.1

newV2.0.genewise.35.14.1

newV2.0.genewise.11.7.1

newV2.0.grail.19.78.1

newV2.0.grail.195.10.1

newV2.0.grail.250.7.1

(newV2.0.genewise.727.3.1)

newV2.0.genewise.11.351.1

newV2.0.genewise.26.99.1

newV2.0.genewise.2.588.1

newV2.0.genewise.39.227.1

newV2.0.genewise.29.9.1

No obvious homolog,

but up to 6 related genes

newV2.0.genewise.5.899.1

newV2.0.genewise.35.111.1

newV2.0.genewise.78.73.1

newV2.0.genewise.13.260.1

$V D E(D D E)$

Summary of the $\mathrm{Chl}$ and carotenoid biosynthetic enzymes that have been identified in vascular plants and of the putative homologous genes found in the genome of T. pseudonana. Enzymes from vascular plants which are involved in the bisynthesis of $\mathrm{Chl} b$ and lutein have been omitted due to the lack of these pigments in diatom.

1 gene names were chosen to present the catalytic function of protein products in best way, otherwise followed to gene designations in Arabidopsis; abbreviations indicative of enzymatic function were preferred. In the case of multiple commonly used synonyms, see Grossman et al. (2004). Throughout the text, the same abbreviations in capital letters are used for enzymes and their coding genes, the latter written in italics.

2 gene models (as of 01.07.2005) accessible at http://genome.jgi-psf.org/thaps1/thaps1.home.html; gene models in brackets are redundant, because the scaffold on which they localize is part of a larger scaffold (with identical nucleotide sequence) containing the other denoted gene model. 
$\underline{\text { Table } 2}$

Plastidic enzymes regulated by TR in Chlorophyta and their mode of regulation in diatoms

\begin{tabular}{ll}
\hline $\begin{array}{l}\text { Calvin cycle } \\
\text { PRK }\end{array}$ & not regulated by TR \\
GAPDH & not regulated by TR \\
FBPase & possibly regulated by TR \\
SBPase & unknown \\
RubisCO Activase & missing in diatom plastids \\
OPP & missing in diatom plastids \\
G6PDH & \\
Lipid synthesis & unknown \\
ACCase & \\
Starch metabolism & missing in diatom plastids \\
AGPase & \\
ATPase & \\
$\quad \gamma$ subunit & not regulated by TR \\
Malate valve & \\
NADP-MDH &
\end{tabular}


Table 3

Summary of Michaelis-Menten Half-saturation constant $\mathrm{K}_{\mathrm{s}}$ for $\mathrm{NO}_{3}, \mathrm{PO}_{4}$ and Si uptake and $\mathrm{K} \mu$ for Fe (From Sarthou et al. 2005)

Julie please check comment 81

\begin{tabular}{|l|l|l|l|}
\hline Nutrient & Range & Mean (+/- s.d.) & $n$ \\
\hline $\mathrm{NO}_{3}(\mu \mathrm{M})$ & $0.02-10.2$ & $1.6(1.9)$ & 35 \\
\hline $\mathrm{PO}_{4}(\mu \mathrm{M})$ & $0.01-8.9$ & $1.2(2.5)$ & 18 \\
\hline $\mathrm{Si}(\mu \mathrm{M})$ & $0.2-22$ & $3.9(5.0)$ & 25 \\
\hline $\mathrm{Fe}(\mathrm{nM})$ & $5.9 \times 10^{-4}-1.12$ & $0.35(0.44)$ & 12 \\
\hline
\end{tabular}




\section{References}

Adamson HY, Hiller RG, Walmsley J (1997) Protochlorophyllide reduction and greening in angiosperms: an evolutionary perspective. J Photochem Photobiol B: Biology 41: 201-221

Adl SM, Simpson AG, Farmer MA, Andersen RA, AndersonOR, Barta JR, Bowser SS, Brugerolle G, Fensome RA, Fredericq S, James, FY, Karpov S, Kugrens P, Krug J, Lane CE, Lewis LA, Lodge J, Lynn DA, Mann DG, McCourt RM, Mendoza L, Moestrup O, Mozley-Standridge SE, Nerad TA, Shearer CA, Smirnov AV, Spiegel, FW, Taylor MF (2005) The new higher level classification of eukaryotes with emphasis on the taxonomy of protists. J Eukaryot Microbiol 52: 399-451

Allen AE (2005) Beyond sequence homology: Redundant ammonium transporters in a marine diatom are not functionally equivalent. J Phycol 41: 4-6

Allen AE, Ward BB, Song B (2005) Characterization of diatom (Bacillariophyceae) nitrate reductase genes and their detection in marine phytoplankton communities. J Phycol 41: 95104

Armbrust EV, Berges JA, Bowler C, Green BR, Martinez D, Putnam NH, Zhou S, Allen AE, Apt KE, Bechner M, Brzezinski MA, Chaal BK, Chiovitti A, Davis AK, Demarest MS, Detter CJ, Glavina T, Goodstein D, Hadi MZ, Hellsten U, Hildebrand M, Jenkins BD, Jurka J, Kapitonov VV, KrögerN, Lau WWY, Lane TW, Larimer FW, Lippmeier JC, Lucas S, Medina M, Montsant A, Obornik M, Schnitzler-Parker M, Palenik B, Pazour GJ, Richardson, PM, Rynearson TA, Saito, MA, Schwartz DC, Thamatrakoln 
K, Valentin K, Vardi A, Wilkerson FP, Rokhsar, DS (2004) The Genome of the Diatom Thalassiosira pseudonana: Ecology, Evolution, and Metabolism. Science 306: 79-86

Asada K (1996) Radical production and scavenging in chloroplasts. In Photosynthesis and the environment (ed. N.R. Baker), Dordrecht, The Netherlands, Kluwer, 123-150

Asada K (1999) The water-water cycle in chloroplasts: scavenging of active oxygens and dissipation of excess photons. Ann Rev Plant Physiol Plant Mol Biol 50: 601-639

Atkinson D, Benjamin J C, Montagnes D J S (2003). Protists decrease in size linearly with temperature: ca. $2.5 \%{ }^{\circ} \mathrm{C}^{-1}$. Proc R Soc Lond B 270: 2605-2611

\begin{abstract}
Badger MR, Andrews TJ, Whitney SM, Ludwig M, Yellowlees DC, Leggat W, Price GD (1998) The diversity and coevolution of Rubisco, plastids, pyrenoids, and chloroplast-based $\mathrm{CO}_{2}$-concentrating mechanisms in algae. Can J Bot 76: 1052-1071
\end{abstract}

Badger MR, von Caemmerer S, Ruuska S, Nakano H (2000) Electron flow to oxygen in higher plants and algae: rates and control of direct photoreduction (Mehler reaction) and rubisco oxygenase. Phil Trans R Soc L 355: 1433-1446

Bassi R, Caffarri S (2000) Lhc proteins and the regulation of photosynthetic light-harvesting function by xanthophylls. Photosynth Res 64: 243-256

Beale SI (1999) Enzymes of chlorophyll biosynthesis. Photosynth. Res. 60: 43-73 
Beardall J (1989) Photosynthesis and Photorespiration in marine Phytoplankton. Aquat Bot 34: $105-130$

Beardall J, Giordano M (2002) Ecological implications of microalgal and cyanobacterial $\mathrm{CO}_{2}$ concentrating mechanisms, and their regulation. Austr J Plant Physiol 29: 335-347.

Beardall J, Quigg A, Raven JA (2003) Oxygen consumption: Photorespiration and chlororespiration. In Larkum AW, Douglas SE, Raven JA (eds) Photosynthesis in algae. Kluwer Academic Publishers, Dordrecht, pp 157-181

Berges JA, Charlebois, DO, Mauzerall, DC, Falkowski PG (1996). Differential effects of nitrogen limitation on photosynthetic efficiency of photosystem I and II in microalgae. Plant Physiol 110: 689-696.

Berges JA, Falkowski PG (1998) Physiological stress and cell death in marine phytoplankton: Induction of protease in response to nitrogen or light limitation. Limnol Oceanogr 43: 129-135.

Berges J, Varela D, Harrison P (2002). Effects of temperature on growth rate, cell composition and nitrogen metabolism in the marine diatom Thalassiosira pseudonana (Bacillariophyceae). Mar Ecol Progr Ser 225: 139-146

Berkaloff C, Caron L, Rousseau B (1990) Subunit organization of PS I particles from brown algae and diatoms: polypeptide and pigment analysis. Photosynth Res 23: 181-193 
Berthold DA, Stenmark P (2003) Membrane-bound diiron carboxylate proteins. Annu. Rev. Plant Biol. 54: 497-517

Bhaya D, Grossman AR (1993) Characterization of gene clusters encoding the fucoxanthin chlorophyll proteins of the diatom P. tricornutum. Nuc Acid Res 21: 4458-4446

Brown J (1988) Photosynthetic pigment organization in diatoms. J Phycol 24: 96-102

Büchel C (2003) Fucoxanthin-chlorophyll proteins in diatoms: The $18 \mathrm{kDa}$ and 19 kDa subunits assemble into different oligomeric states. Biochem 42: 13027-13034

Burkhard S, Zondervan I, Riebesell U (1999) Effect of $\mathrm{CO}_{2}$ concentration on the C:N:P ratio in marine phytoplankton: A species comparison. Limnol Oceanogr 44: 683-690

Burkhardt S, Amoroso G, Riebesell U, Sültemeyer D (2001) $\mathrm{CO}_{2}$ and $\mathrm{HCO}_{3}{ }^{-}$uptake in marine diatoms acclimated to different $\mathrm{CO}_{2}$ concentrations. Limnol Oceanogr 46: 1378-1391

Burrows PA, Sazanov LA, Svab Z, Maliga P, Nixon P (1998) Identification of a functional respiratory complex in chloroplasts through analysis of tobacco mutants containing disrupted plastid $n d h$ genes. EMBO J 17: 868-876

Cadoret J-C, Demoulière R, Lavaud J, van Gorkom HJ, Houmard J, Etienne A-L (2005)

Dissipation of excess energy triggered by blue light in cyanobacteria with CP43' (isiA). Biochim Biophys Acta Bioenergetics 1659: 100-104 
Carol P, Stevenson D, Bisanz C, Breitenbach J, Sandmann G, Mache R, Coupland G, Kuntz M (1999) Mutations in the Arabidopsis gene IMMUTANS cause a variegated phenotype by inactivating a chloroplast terminal oxidase associated with phytoene desaturation. Plant Cell 11: 57-68

Chang CW, Moseley JL, Wykoff D, Grossman AR (2005). The LPB1 gene is important for acclimation of Chlamydomonas reinhardtii to phosphorus and sulfur deprivation. Plant Physiol 138: 319-329

Claquin P, Martin-Jezequel V (2002). Uncoupling of silicon compared with carbon and nitrogen metabolisms and the role of the cell cycle in continuous cultures of Thalassiosira pseudonana (Bacillariophyceae) under light, nitrogen, and phosphorus control. J Phycol 38: $922-930$.

Claquin P, Kromkamp JC, Martin-Jezequel V (2004) Relationship between photosynthetic metabolism and cell cycle in a synchronized culture of the marine alga Cylindrotheca fusiformis (Bacillariophyceae). Eur J Phycol 39: 33-41

Clark D, Flynn KJ, Owens NJP (2002) The large capacity for dark nitrate-assimilation in diatoms may overcome nitrate limitation of growth. New Phytologist 155: 101-108.

Collos Y, Vaquer A, Souchu P (2005). Acclimation of nitrate uptake by phytoplankton to high substrate levels. J Phycol 41: 466-478 
Cunningham Jr FX, Gantt E (1998) Genes and enzymes of carotenoid biosynthesis in plants. Annu Rev Plant Physiol Plant Mol Biol 49: 557-583

Cvejić JH, Rohmer M (2000) $\mathrm{CO}_{2}$ as main carbon source for for isoprenoid biosynthesis via the mevalonate-independent methylerythritol 4-phosphate route in the marine diatoms Phaeodactylum tricornutum and Nitzschia ovalis. Phytochemistry 53: 21-28

Dekker JP, Boekema EJ (2005) Supramolecular organization of thylakoid membrane proteins in green plants. Biochim Biophys Acta 1706: 12-39

Dish A, Schwender J, Müller C., Lichtenthaler HK, Rohmer M (1998) Distribution of the mevalonate and glyceraldehyde phosphate/pyruvate pathways for isoprenoid biosynthesis in unicellular algae and the cyanobacterium Synechocystis PCC 6714. Biochem J 333: 381-388

Eckhardt U, Grimm B, Hörtensteiner S (2004) Recent advances in chlorophyll biosynthesis and breakdown in higher plants. Plant Mol Biol 56: 1-14

Eicks M, Maurino V, Knappe S, Flügge UI, Fischer K (2002) The plastidic pentose phosphate translocator represents a link between the cytosolic and the plastidic pentose phosphate pathways in plants. Plant Physiol 128: 512-522

Eisner LB, Twardowski MS, Cowles TJ, Perry MJ (2003) Resolving phytoplankton photoprotective: photosynthetic carotenoid ratios on fine scales using in situ absorption measurements. Limnol Oceanogr 48: 632-646 
Elzenga JTM, Prins HBA, Stefels J (2000) The role of extracellular carbonic anhydrase activity in inorganic carbon utilization of Phaeocystis globosa (Prymnesiophyceae): A comparison with other marine algae using the isotope disequilibrium technique. Limnol Oceanogr 45: 372-380

Endo T, Shikanai T, Takabayashi A, Asada K, Sato F (1999) The role of chloroplastic $\mathrm{NAD}(\mathrm{P}) \mathrm{H}$ dehydrogenase in photoprotection. FEBS Lett 457: 5-8

Eppard M, Rhiel E (1998) The genes encoding light-harvesting subunits of Cyclotella cryptica (Bacillariophyceae) constitute a complex and heterogeneous family. Mol Gen Genet 260: $335-345$

Falciatore A, Bowler C (2002) Revealing the molecular secrets of marine diatoms. Annu Rev Plant Biol 53: 109-130

Falkowski PG, Raven JA (1997) Aquatic Photosynthesis, Blackwell Science, Malden, MA.

Falkowski PG, Katz ME, Knoll AH, Quigg A, Raven JA, Schofield O, Taylor FJR (2004) The evolution of modern eukaryotic phytoplankton. Science 305: 354-360.

Farr TJ, Huppe HC, Turpin DH (1994) Coordination of chloroplastic metabolism in Nimited C. reinhardtiiby redox modulation (I. The activation of phosphoribulosekinase and glucose-6-phosphate dehydrogenase is relative to the photosynthetic supply of electrons). Plant Physiol 105: 1037-1042 
Fey V, Wanger R, Bräutigam K, Wirtz M, Hell R, Dietzmann A, Leister D, Oehlmueller R, Pfannschmidt T (2005) Retrograde plastid redox signals in the Expression of Nuclear Genes for chloroplast proteins of Arabidopsis thaliana. J Biol Chem 280: 5318-5328

Fogg GE (1991) The phytoplanktonic ways of life. New Phytol 118: 191-232

Furusato E, Asaeda T, Manatunge, J. (2004). Tolerance for prolonged darkness of three phytoplankton species, Microcystis aeruginosa (Cyanophyceae), Scenedesmus quadricauda (Chlorophyceae), and Melosira ambigua (Bacillariophyceae). Hydrobiologia 527: 153-162.

Geider RJ, LaRoche J (2002) Redfield revisited: variability of C:N:P in marine microalgae and its biochemical basis. Eur J Phycol 37: 1-17

Geigenberger P, Kolbe A, Tiessen A (2005) Redox regulation of carbon storage and partitioning in response to light and sugars. J Exp Botany 56: 1469-1479

Gilbert M, Wilhelm C, Richter M (2000) Bio-optical modelling of oxygen evolution using in vivo fluorescence: Comparison of measured and calculated photosynthesis/irradiance (P-I) curves in four representative phytoplankton soecies. J Plant Physiol 157: 307-314

Giordano M, Beardall J, Raven, JA (2005) $\mathrm{CO}_{2}$ concentrating mechanisms in algae. mechanisms, environmental modulation and evolution. Annu Rev Plant Bio. 56: 99-131. 
Gleitz, M., Bartsch A., Dieckmann G.S., Eicken H. (1998) Composition and succession of sea ice diatom assemblages in the eastern and southern Weddell Sea, Antarctica. In: Lizotte M.P., Arrigo K.R. (eds.) Antarctic sea ice - biological processes, interactions and variability. Antarctic Research Series, American Geophysical Union, Washington, D.C., pp 107-120.

Glöckner G, Rosenthal A, Valentin K (2000) The structure and gene repertoire of an ancient red algal plastid genome. J Mol Evol 51: 382-390

Goericke R, Welschmeyer NA (1992a) Pigment turnover in the marine diatom Thalassiosira weissflogii. I. The ${ }^{14} \mathrm{CO}_{2}$-labeling kinetics of chlorophyll $a$. J Phycol 28: 498-507

Goericke R, Welschmeyer NA (1992b) Pigment turnover in the marine diatom Thalassiosira weissflogii. II. The ${ }^{14} \mathrm{CO}_{2}$-labeling kinetics of carotenoids. J Phycol 28: 507-517

Goss R, Lohr M, Latowski D, Grzyb J, Vieler A, Wilhelm C, Strzalka K (2005) Role of hexagonal structure forming lipids in diadinoxanthin and violaxanthin solubilization and deepoxidation. Biochemistry 44: 4028-4036

Goldschmidt-Clermont M (1998) Coordination of nuclear and chloroplast gene expression in plant cells. Int Rev Cytol 177: 115-180

Graciet E, Lebreton S, Gontero B (2004) Emergence of new regulatory mechanisms in the Benson-Calvin pathway via protein-protein interactions: a glyceraldehyde-3-phosphate dehydrogenase/CP12/phosphoribulokinase complex. J Exp Botany 55: 1245-1254 
Granum E, Myklestad SM (2002) A simple combined method for determination of $\beta-1,3-$ glucanand cell wall polysaccharides in diatoms. Hydrobiologia 477: 155-161

Granum E, Kirkvold S, Myklestad SM (2002) Cellular and extracellular production of carbohydrates and amino acids by the marine diatom Skeletonema costatum: diel variations and effects of $\mathrm{N}$ depletion. Mar Ecol Progr Ser 242: 82-93

Grouneva I, Jakob T, Wilhelm C, Goss R (2006) Influence of ascorbate and pH on the activity of the diatom xanthophyll cycle-enzyme diadinoxanthin de-epoxidase. Physiologia Plantarum in press

Green BR (2003) The evolution of light-harvesting antennas. In Green BR, Parson WW (eds) Light-harvesting antennas in photosynthesis. Kluwer Academic Publishers, Dordrecht / Boston / London, pp 129-168

Grossman AR, Lohr M, Im CS (2004) C. reinhardti in the landscape of pigments. Annu Rev Genet 38: 119-173

Guglielmi G, Lavaud J, Rousseau B, Etienne A-L, Houmard J, Ruban AV (2005) The light-harvesting antenna of the diatom P. tricornutum: Evidence for a diadinoxanthin binding sub-complex. FEBS J 272: 4339-4348

Guerrini F, Cangini M, Boni L, Trost P, Pistocchi P (2000). Metabolic responses of the diatom Achnanthes brevipes to nutrient limitation. J Phycol 36: 882-890. 
Hager A (1969) Lichtbedingte pH-Erniedrigung in einem Chloroplasten-Kompartiment als Ursache der enzymatischen Violaxanthin-Zeaxanthin-Umwandlung; Beziehungen zur Photophosphorylierung. Planta 89: 224-243

Hager A (1975) Die reversiblen lichtabhängigen Xanthophyllumwandlungen im Chloroplasten. Ber Dtsch Bot Ges 88: 27-44

Hager A, Holocher K (1994) Localization of the xanthophyll-cycle enzyme violaxanthin deepoxidase within the thylakoid lumen and abolition of its mobility by a (light-dependent) $\mathrm{pH}$ decrease. Planta 192: 581-589

Hagopian JC, Reis M, Kitajima JP, Bhattacharya D, de Olivera MC (2004) Comparative analysis of the complete plastid genome sequence of the red alga Gracilaria tenuistipitata var. liui provides insight into the evolution of rhodoplasts and their relationship to other plastids. $\mathbf{J}$ Mol Evol 59: 464-477

Hamm CE, Merkel R, Springer O, Jurkojc P, Maier C, Prechtel K, Smetacek V (2003) Architecture and material properties of diatom shells provide effective mechanical protection. Nature 421: 841-843.

Hertig C.M., Wolosiuk R.A. (1983) Studies on the hysteretic properties of chloroplast fructose-1,6-bisphosphatase. J Biol Chem 258: 984 - 989 
Hildebrand M, Dahlin K, Volcani BE (1998) Characterization of a silicon transporter gene family in Cylindrotheca fusiformis: sequences, expression analysis, and identification of homologues in other diatoms. Mol Gen Genetics 260: 480-486.

Hildebrand M (2005) Cloning and functional characterization of ammonium transporters from the marine diatom Cylindrotheca fusiformis (Bacillariophyceae). J Phycol 41: 105-113

Hirschberg J (2001) Carotenoid biosynthesis in flowering plants. Curr Opin Plant Biol 4: 210-218

Hisabori T, Hara S, Fujii T, Yamazaki D, Hosoya-Matsuda N, Motohashi K (2005) THIOREDOXIN affinity chromatography: a useful method for further understanding the thioredoxin network. J Exp Botany 56: 1463-1468

Holt NE, Fleming GR, Niyogi KK (2004) Toward an understanding of the mechanism of non-photochemical quenching in green plants. Biochemistry: 43, 8281-8289

Horton P, Ruban AV, Wentworth M (2000) Allosteric regulation of the light-harvesting system of Photosystem II. Phil Trans R Soc Ser B 355: 1361-1370

Huisman J, Sharples J, Stroom JM, Visser PM, Kardinaal WEA, Verspagen JMH, Sommeijer B (2004) Changes in turbulent mixing shift competition for light between phytoplankton species. Ecology 85 : 2960-2970 
Ivanov B, Asada K, Kramer DM, Edwards G (2005) Characterization of photosynthetic electron transport in bundle sheath cells of maize. I. Ascorbate effectively stimulates cyclic electron flow around PSI. Planta 220: 572-581

Jacquot JP, Lancelin JM, Meyer Y (1997) Thioredoxins: structure and function in plant cells. New Phytol 136: 543-570

Jakob T, Goss R, Wilhelm C (1999) Activation of diadinoxanthin deepoxidase due to a chlororespiratory proton gradient in the dark in the diatom P. tricornutum. Plant Biology, 1: $76-83$

Jakob T, Goss R, Wilhelm C (2001) Unusual pH-dependence of diadinoxanthin deepoxidase activation causes chlororespiratory induced accumulation of diatoxanthin in the diatom Phaeodactylum tricornutum. J Plant Physiol 158: 383-390

Jakob T, Schreiber U, Kirchesch V, Langner U, Wilhelm C (2005) Estimation of chlorophyll content and daily primary production of the major algal groups by means of multiwavelength-excitation PAM chlorophyll fluorometry: performance and methodological limits. Photosynth Res 83: 343-361

Jeffrey SW (1989) Chlorophyll c pigments and their distribution in the chromophyte algae. In Green JC, Leadbeater BSC Diver WL (eds) The Chromophyte Algae: Problems and Perspectives. Clarendon Press, Oxford, pp 13-36 
Jensen RA (1985) The shikimate/arogenate pathway: Link between carbohydrate metabolism and secondary metabolism. Physiol Plant 66: 164-168

Kashino Y, Kudoh S, Hayashi Y, Suzuki Y, Odate T, Hirawake T, Satoh K, Fukuchi M (2002) Strategies of phytoplankton to perform effective photosynthesis in the North Water. Deep-Sea Res Pt II 49: 5049-5061

Ketcham SR, Davenport JW, Warncke K, McCarty RE(1984) Role of the gamma subunit of chloroplast coupling factor 1 in the light- dependent activation of photophosphorylation and ATPase activity by dithiothreitol. J Biol Chem 259: 7286-7293.

Kilian O, Kroth PG (2004) Presequence acquisition during secondary endocytobiosis and the possible role of introns. J Mol Evol 58: 712-721

Kilian O, Kroth PG (2005) Identification and characterization of a new conserved motif within the presequence of proteins targeted into complex diatom plastids: Plant J 41: 175-183

Korb RE, Saville PJ, Johnston AM, Raven JA (1997) Sources of inorganic carbon for photosynthesis by three species of marine diatom. J Phycol 33: 433-440.

Kowallik KV, Stoebe B, Schaffran I, Kroth-Pancic P, Freier U (1995) The chloroplast genome of a chlorophyll a+c containing alga, Odontella sinensis. Plant Mol Biol Rep 13: 336342 
Kroger N, Lorenz S, Brunner EM, Sumper M (2002) Self-Assembly of Highly Phosphorylated Silaffins and Their Function in Biosilica Morphogenesis. Science 298: 584586.

Külheilm C, Agren J, Jansson S (2002) Rapid regulation of light-harvesting and plant fitness in the field. Science 297: 91-93

La Fontaine S, Quinn JM, Nakamoto SS, Page MD, Gohre V, Moseley JL, Kropat J, Merchant S (2002) Copper-Dependent Iron Assimilation Pathway in the Model Photosynthetic Eukaryote Chlamydomonas reinhardtii. Eukaryotic Cell 1: 736-757.

Lane TW, Saito MA, George GN, Pickering IJ, Prince RC, Morel FMM (2005) A cadmium enzyme from a marine diatom. Nature 435: 42

LaRoche J, Boyd PW, McKay ML, Geider RJ (1996) Flavodoxin as an in-situ marker for iron stress in phytoplankton. Nature 382: 802-805

LaRoche JRM, McKay L, Boyd P (1999) Immunological and molecular probes to detect phytoplankton responses to environmental stress in nature. Hydrobiologia 401: 177-198

Latowski D, Kruk J, Burda K, Skrzynecka-Jaskier M, Kostecka-Gugala A, Strzalka K (2002) Kinetics of violaxanthin de-epoxidation by violaxanthin de-epoxidase, a xanthophyll cycle enzyme, is regulated by membrane fluidity in model lipid bilayers. Eur J Biochem 269: $4656-4665$ 
Lavaud J, Rousseau B, van Gorkom HJ, Etienne A-L (2002a) Influence of the diadinoxanthin pool size on photoprotection in the marine planktonic diatom Pheaodactylum tricornutum. Plant Physiol 129: 1398-1406

Lavaud J, Rousseau B, Etienne A-L (2002b) In diatoms, a transthylakoid proton gradient alone is not sufficient to induce a non-photochemical fluorescence quenching. FEBS Lett 523: $163-166$

Lavaud J, van Gorkom HJ, Etienne A-L (2002c) Photosystem II electron transfer cycle and chlororespiration in planktonic diatoms. Photosynth Res 74: 51-59

Lavaud J, Rousseau B, Etienne A-L (2003) Enrichment of the light-harvesting complex in diadinoxanthin and implications for the non-photochemical fluorescence quenching in diatoms. Biochemistry 42: 5802-5808

Lavaud J, Rousseau B, Etienne A-L (2004) General features of photoprotection by energy dissipation in planktonic diatoms (Bacillariophyceae). J Phycol 40: 130-137

\section{Leboulanger C, Martin-Jezequel V, Descolas-Gros C, Sciandra A, Jupin HJ (1998)} Photorespiration in continuous cultures of Dunaliella tertiolecta (Chlorophyta): relationships between serine, glycine, and extracellular glycolate. J Phycol 34: 651-654

Leventer A (1998) The fate of Antarctic sea-ice diatoms and their use as paleoenvironmental indicators. In: Lizotte MP, Arrigo KR (eds.) Antarctic sea ice - biological processes, 
interactions and variability. Antarctic Research Series, American Geophysical Union, Washington, D.C., pp 121-138

Liaud MF, Lichtle C, Apt K, Martin W, Cerff R (2000) Compartment-specific isoforms of TPI and GAPDH are imported into diatom mitochondria as a fusion protein: Evidence in favor of a mitochondrial origin of the eukaryotic glycolytic pathway. Mol Biol Evol 17: 213223

Lippemeier S, Hitze R, Vaselow KH, Hartig P, Colijn F (2001) In-line recording of PAM fluorescence of phytoplankton cultures as a new tool for studying effects of fluctuating nutrient supply on photosynthesis. Eur J Phycol 36: 89-100.

Litchman E, Klausmeier CA (2001) Competition of phytoplankton under fluctuating light. Am Nat 157: 171-187

\section{Liu Z, Yan H, Wang K, Kuang T, Zhang J, Gui L, An X, Chang W (2004)} Crystal structure of spinach major light-harvesting complex at $2.72 \AA$ resolution. Nature $\mathbf{4 2 8}$ : $287-292$

Lohr M, Wilhelm C (1999) Algae displaying the diadinoxanthin cycle also possess the violaxanthin cycle. Proc Natl Acad Sci USA 96: 8784-8789

Lohr M, Wilhelm C (2001) Xanthophyll synthesis in diatoms: quantification of putative intermediates and comparison of pigment conversion kinetics with rate constants derived from a model. Planta 212: 382-391 
Lohr M, Im C-S, Grossman AR (2005) Genome-based examination of chlorophyll and carotenoid biosynthesis in Chlamydomonas reinhardtii. Plant Physiol 138: 490-515

Los DA, Murata N (2004) Membrane fluidity and its roles in the perception of environmental signals. Biochim Biophys Acta 1666: 142-157.

MacIntyre HL, Kana TM Geider RJ (2000) The effect of water motion on short-term rates of photosynthesis by marine phytoplankton. Trends Plant Sci 5: 12-17

Maheswari U, Montsant A, Goll J, Krishnasamy S, Rajyashri KR, Morawala Patell V, Bowler C (2005). The diatom EST database. Nucl Acide Res. 33: 344-347

Mano J, Hideg E, Aasada K (2004) Ascorbate in thylakoid lumen functions as an alternative electron donor to photosystem II and photosystem I. Arch Biochem Biophys 429: 71-80

Martin B, (2003) Gene transfer from organelles to the nucleus: frequent and big chunks. Proc Natl Acad Sci USA 100: 8612-8614

Martin W, Scheibe R, Schnarrenberger C (2000) The calvin cycle and ist regulation. In: Photosynthesis: Physiology and Metabolism. (von Caemmerer, ed.). Kluwer Acad. Press, Dordrecht, pp. 10-51. 
Martin-Jézéquel V, Hildebrand M, Brzezinski MA (2000) Silicon metabolism in diatoms: implications for growth. J Phycol 36: 821-840

Massé G, Belt ST, Rowland SJ, Rohmer M (2004) Isoprenoid biosynthesis in the diatoms Rhizosolenia setigera (Brightwell) and Haslea ostrearia (Simonsen). Proc Natl Acad Sci USA 101: 4413-4418

Medlin LK, Kaszmarska I (2004) Evolution of diatoms V. Morphological and cytological support for the major clades and a taxonomic revision. Phycologia 43: 245-270

Mewes H, Richter M (2002) Supplementary ultraviolet-B radiation induces a rapid reversal of the diadinoxanthin in the strong light-exposed diatom Phaeodactylum tricornutum. Plant Physiol 130: 1527-1535

Meyer AA, Tackx M, Daro, N (2000) Xanthophyll cycling in Phaeocystis globosa and Thalassiosira sp.: a possible mechanism for species succession. J Sea Res 43: 373-384

Michels A, Wedel N, Kroth PG (2005) Diatom Plastids Possess a Phosphoribulokinase with an Altered Regulation and No Oxidative Pentose Phosphate Pathway. Plant Physiol 137: 911920

Milligan AJ, Harrison PJ (2000). Effects of non-steady-state iron limitation on nitrogen assimilatory enzymes in the marine diatom Thalassiosira weissflogii (Bacillariophyceae). $\mathrm{J}$ Phycol 36: 78-86 
Mock T, Valentin K (2004) Photosynthesis and cold acclimation: molecular evidence fro a polar diatom. J Phycol 40: 732-741

Mock T, Krell A, Glöckner G, Kolukisaoglu Ü, Valentin K (2005) Analysis of expressed sequence tags (EST) from the polar diatom Fragilariopsis cylindrus. J. Phycology, in press

Montsant A, Jabbari K, Maheswari U, Bowler C (2005) Comparative genomics of the pennate diatiom P. tricornutum. Plant Physiol 137: 500-513.

Moseley JL, Allinger T, Herzog S, Hoerth P, Wehinger E, Merchant S, Hippler M (2002) Adaptation to Fe-deficiency requires remodeling of the photosynthetic apparatus. EMBO J 21: $6709-6720$.

Müller AM, Wilhelm C (1997) The adaptation of the phytoplankton diatom P. tricornutum to light stress under the conditions of a natural light climate. Revue Inter Hydrobiol 82: 315328

Murphy AM, Cowles TJ (1997) Effects of darkness on multiexcitation in-vivo fluorescence and survival in a marine diatom. Limnol Oceanogr 42: 1444-1453

Nagata N, Tanaka R, Satoh S, Tanaka A (2005) Identification of a vinyl reductase gene for chlorophyll synthesis in Arabidopsis thaliana and implications for the evolution of Prochlorococcus species. Plant Cell 17: 233-240 
Ocheretina O, Haferkamp I, Tellioglu H, Scheibe R (2000) Light-modulated NADPmalate dehydrogenases from mossfern and green algae: insights into evolution of the enzyme's regulation. Gene 258: 147-154

Ohta N, Matsuzaki M, Misumi O, Miyagishima S, Nozaki H, Tanaka K, Shin-I T, Kohara Y, Kuroiwa T (2003) Complete sequence and analysis of the plastid genome of the unicellular red alga Cyanidioschyzon merolae. DNA Res 10: 67-77

Ort DR, Baker NR (2002) A photoprotective role for $\mathrm{O}_{2}$ as an alternative electron sink in photosynthesis? Curr Opinion Plant Biol 5: 193-198

Owens TG, Riper DM, Falkowski PG (1978) Studies of delta-aminolevulinic acid ehydratase from Skeletonema costatum, a marine plankton diatom. Plant Physiol 62: 516-521

Owens TG (1988) Light-harvesting antenna systems in the chlorophyll a/c-containing algae. In: Light-energy transduction in photosynthesis, pp 122-136, Stevens, Bryant, eds., Am. Soc. Plant physiologists, Rockville, Maryland

Owens TG (1986) Light-harvesting function in the diatom Phaeodactylum tricornutum. II. Distribution of excitation energy between the photosystems. Plant Physiol 80: 739-746

Paasche E (1960) Phytoplankton distribution in the Norwegian Sea in June, 1954, related to hydrography and compared with primary production data. Fisk Skr Havund 12:1-77 
Palmer JD (2003) Organelle genomes: The symbiotic birth and spread of plastids: how many times and whodunit? J Phycol 39: 4-11

Pancic PG, Strotmann H (1993): Structure of the nuclear encoded $\gamma$ subunit of $\mathrm{CF}_{0} \mathrm{CF}_{1}$ of the diatom Odontella sinensis including its presequence. FEBS Lett. 320: 61-66

Papagiannakis E, van Stokkum I, Fey H, Büchel C, van Grondelle R (2005) Spectroscopic characterisation of the excitation energy transfer in the fucoxanthin-chlorophyll protein of diatoms. Photosynth Res 86: $241-250$

Patron NJ, Rogers MB, Keeling PJ (2004) Gene Replacement of Fructose-1,6-Bisphosphate Aldolase Supports the Hypothesis of a Single Photosynthetic Ancestor of Chromalveolates. Euk. Cell 3: 1169-1175

Paul JS, Volcani BE (1976) Photorespiration in diatoms. IV: Two pathways of glycolate metabolism in synchronized cultures of Cylindrotheca fusiformis Arch Microbiol 110: 247252

Peltier G, Schmidt GW (1991) Chlororespiration: an adaptation to nitrogen deficiency in Chlamydomonas reinhardtii. Proc Natl Acad Sci USA 88: 4791-4795

Pennington F, Guillard RRL, Liaaen-Jensen S (1988): Carotenoid distribution patterns in Bacillariophyceae (diatoms). Biochem Syst Ecol 16: 589-592 
Pfündel E, Renganathan M, Gilmore AM, Yamamoto HY, Dilley RA (1994) Intrathylakoid $\mathrm{pH}$ in isolated pea chloroplasts as probed by violaxanthin de-epoxidation. Plant Physiol 106: 1647-1658

Peters E, Thomas DN (1996). Prolonged darkness and diatom mortality.1. Marine Antarctic species. J Exp Mar Biol Ecol 207: 25-41.

Plettner I (2002) Stress physiology of antarctic ice diatoms: Ecophysiological experiments with respect to the role of proline during acclimatisation to high salinities and low temperatures. Dissertation, University Bremern, Germany

Porra RJ (1997) Recent progress in porphyrin and chlorophyll biosynthesis. Photochem Photobiol 65: 492-516

Quigg, AZ, Finkel V, Irwin AJ, Rosenthal Y, Ho TY, Reinfelder TR, Schofield O, Morel FMM, Falkowski PG 2003) The evolutionary inheritance of elemental stoichiometry in marine phytoplankton. Nature 425: 291-294.

Raven JA (1983). The Transport and Function of Silicon in Plants. Biol Rev Cambridge Phil Soc 58: 179-207.

Reinfelder JR, Kraepel AM, Morel FMM (2000) Unicellular C4 photosynthesis in a marine diatom. Nature 407: 996-999

Reinfelder JR, Milligan AJ, Morel FMM (2004) The role of the C4 pathway in carbon accumulation and fixation in a marine diatom. Plant Physiol 135: 2106-2111 
Reith M, Munholland J (1993) A high-resolution gene map of the chloroplast genome of the red alga Porphyra purpurea. Plant Cell 5: 465-475

Riebesell U (2000) Carbon fix for a diatom. Nature 407: 959-960

Riebesell U, Zondervan I, Rost B, Tortell PD, Zeebe RE, Morel FMM (2000) Reduced calcification in marine plankton in response to increased atmospheric $\mathrm{CO}_{2}$. Nature 407: 634637

Rost B, Riebesell U, Burkhardt S, Sültemeyer D (2003) Carbon acquisition of bloomforming marine phytoplankton. Limnol Oceanogr 48: 55-67

Riper DM, Owens TG, Falkowski PG (1979) Chlorophyll turnover in Skeletonema costatum, a marine plankton diatom. Plant Physiol. 64: 49-54

Rodriguez-Concepcion M, Boronat A (2002) Elucidation of the methylerythritol phosphate pathway for isoprenoid biosynthesis in bacteria and plastids. A metabolic milestone achieved through genomics. Plant Physiol 130: 1079-1089

Rogl H, Schöde R, Lokstein H, Kühlbrandt W, Schubert A (2002) Assignment of spectral substructures to pigment-binding sides in higher plant light-harvesting complex LHC-II. Biochemistry 41: 2281-2287 
Ruban AV, Lavaud J, Rousseau B, Guglielmi G, Horton P, Etienne A-L (2004) The super-excess energy dissipation in diatom algae: comparative analysis with higher plants. Photosynth Res 82: 165-175

Ruelland E, Miginiac-Maslow M (1999) Regulation of chloroplast enzyme activities by thioredoxin: activation or relief from inhibition? Trends in Plant Sci 4: 136-141

Rutherford JC, Bird AJ (2004) Metal-Responsive Transcription Factors That Regulate Iron, Zinc, and Copper Homeostasis in Eukaryotic Cells. Eukaryotic Cell 3: 1-13

Sakshaug E, Demers S, Yentsch, CM (1987) Thalassiosira oceanica and T. pseudonana: two different photoadaptational responses. Mar Ecol Prog Ser 41: 275-282

Sarthou G, Timmermans KR, Blain S, Tréguer P (2005) Growth physiology and fate of diatoms in the ocean: a review. J Sea Res 53: 25-42.

Scheibe R (2004) Malate valves to balance cellular and energy supply. Physologia Plantarum 120: $21-26$

Schnitzler Parker M, Armbrust EV (2004) Induction of photorespiration by light in the centric diatom Thalassiosia weissflogii (Bacillariophyceae): molecular characterization and physiological consequences. J Phycol 40: 557-567 
Shifrin NS, Chisholm SW (1981) Phytoplankton lipids: interspecific differences and effects of nitrate, silicate and light-dark cycles. J.Phycol 17: 374-384.

Shikanai T, Endo T, Hashimoto T, Yamada Y, Asada K, Yokota A (1998) Directed disruption of the tobacco $n d h B$ gene impairs cyclic electron flow around photosystem I. Proc Natl Acad Sci USA 95: 9705-9709

Siefermann D, Yamamoto HY (1975) Properties of NADPH and oxygen-dependent zeaxanthin epoxidation in isolated chloroplasts. A transmembrane model for the xanthophyll cycle. Arch Biochem Biophys 171: 70-77

Standfuss J, van Scheltinga ACT, Lamborghini M, KühlbranDtx W (2005) Mechanisms of photoprotection and nonphotochemical quenching in pea light-harvesting complex at $2.5 \AA$ resolution. EMBO J 24: 919-928

Stauber JL, Jeffrey SW (1988) Photosynthetic pigments in fifty-one species of marine diatoms. J Phycol 24: 158-172

Stransky H, Hager A (1970) Das Carotinoidmuster und die Verbreitung des lichtinduzierten Xanthophyllzyklus in verschiedenen Algenklassen. Arch Mikrobiol 73: 315-323

Stroch M, Spunda V, Kurasova I (2004) Non-radiative dissipation of absorbed excitation energy within photosynthetic apparatus of higher plants. Photosynthetica 42: 323-337 
Strzepeck RJ, Harrisson PJ (2004) Photosynthetic architecture differs in coastal and oceanic diatoms. Nature 431: 689-692

Sun N, Ma L, Pan D, Zhao H, Deng XW. (2003) Evaluation of light regulatory potential of Calvin cycle steps based on large-scale gene expression profiling data. Plant Mol. Biol. 53: $467-478$

Sunda WG, Huntsman S (1997) Interrelated influence of iron, light and cell size on marine phytoplankton growth. Nature 390: 389-392

Thomas DN, Dieckmann GS (2002) Antarctic sea ice a habitat for extremophiles. Science 295: 641-644

Tortell PD (2000) Evolutionary and ecological perspectives on carbon acquisition in phytoplankton. Limnol Oceanogr 45: 744-750

Valentin K, Fischer S, Cattolico RA (1998) The chloroplast $b c h I$ gene encodes a subunit of magnesium chelatase in the marine heterokont alga Heterosigma carterae. Eur J Phycol 33: $113-120$

Vårum KM, Myklestad S (1984) Effects of light, salinity and nutrient limitation on the production of $\beta$-1,3-D-glucan and exo- D-glucanase activity in Skeletonema costatum (Grev.) Cleve. J Exp Mar Biol Ecol 83: 13-26. 
Vavilin DV, Vermaas WFJ (2002) Regulation of the tetrapyrrole biosynthetic pathway leading to heme and chlorophyll in plants and cyanobacteria. Physiol Plant 115: 9-24

Waller RF et al. (1998) Nuclear-encoded proteins target to the plastid in Toxoplasmagondii and Plasmodium falciparum. Proc Natl Acad Sci USA 95: 12352-57

Wagner H, Jakob T, Wilhelm C (2006) Balancing the energy flow from captured light to iomass under fluctuating light conditions. New Phytol 169: 95-108

Whitmarsh J, Pakrasi HB (1996) Form and function of cytochrom b-559. In: Oxygenic Photosynthesis: The light reactions. Ort DR, Yocum CF (eds.), Kluwer Academic Publishers, Dordrecht, The Netherlands, pp. 249-264

Wingler A, Lea PJ, Quick WP, Leegood RC (2000) Photorespiration: metabolic pathways and their role in stress protection. Phil Trans R Soc London 355: 1517-1529

Winkler U, Stabenau, H (1992) Compartmentation of peroxisomal enzymes in the diatom Fragilaria, In: Phylogenetic changes in peroxisomes of algae- Phylogeny of plant peroxisomes, pp. 130- 139, Stabenau, H. ed. University Press, Oldenburg.

Winkler U, Stabenau H (1995) Isolation and characterization of peroxisomes from diatoms. Planta 195: 403-407

Wedel N, Soll J (1998) Evolutionary conserved light regulation of Calvin cycle activity by NADPH-mediated reversible phosphoribulokinase / CP12 / glyceraldehyde-3-phosphate dehydrogenase complex dissociation. Proc Natl Acad Sci USA 95: 9699-9704 
Yamamoto HY, Nakayama TOM, Chichester CO (1962) Studies on the light interconversions of the leaf xanthophylls. Arch Biochem Biophys 97: 168-173

Zhang N, Portis Jr AR (1999) Mechanisms of light regulation of Rubisco: a specific role for larger Eubisco activase isoform involving reductive activation by thioredoxin-f. Proc Natl Acad USA 96: 9438-9443

Zaslavskaia LA, Lippmeier JC, Shih C, Ehrhardt D, Grossman AR, Apt K (2001) Trophic conversion of an obligate photoautotrophic organism through metabolic engineering. Science 292: 2073-2075 


\section{Algae with primary plastids (Chlorophytes, rhodophytes glaucopyhtes)}
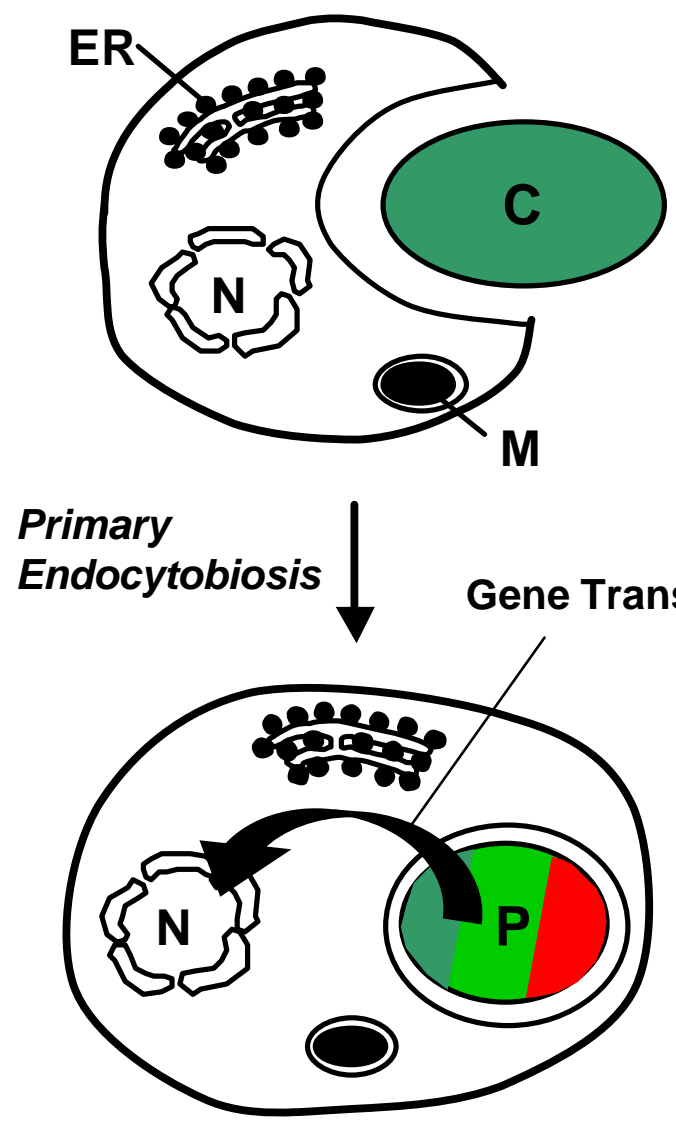

\section{Algae with secondary plastids and CER (Diatoms, brown algae and related algae)}

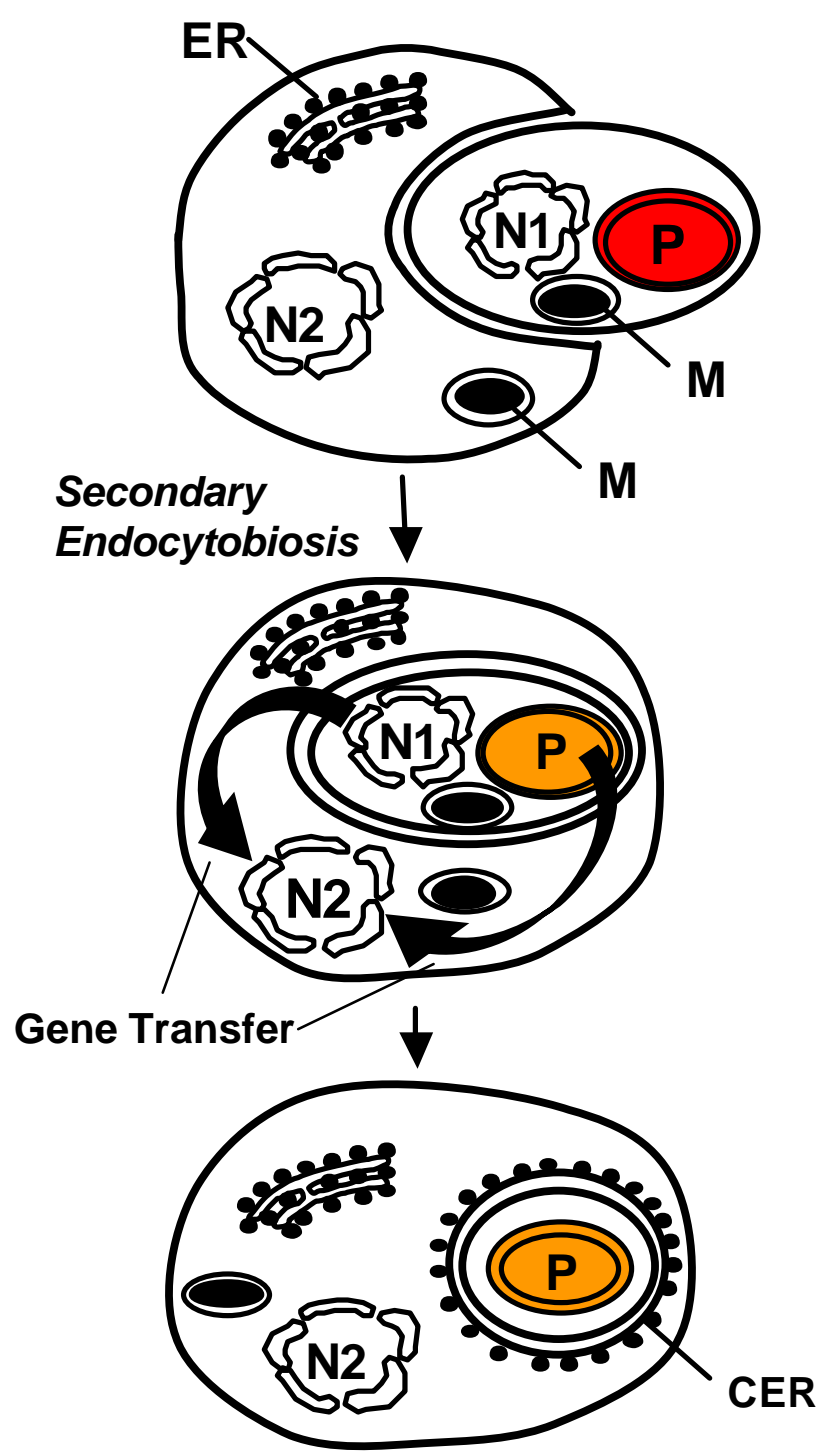

Figure 1: Schematic cartoon describing the putative origin of algae with primary and secondary plastids by primary or secondary endocytobiosis, respectively. Primary plastids are supposed to originate from a cyanobacterium that was engulfed by a heterotrophic host cell and subsequently transformed into an organelle. Living groups are chlorophytes, rhodophytes and glaucophytes. Diatoms, brown algae, and some related groups evolved by secondary endocytobiosis: A unicellular ancestor of modern red algae was taken up and reduced to a plastid. This process resulted in additional membranes surrounding the plastids. Furthermore the reduction of all cytoplasmic components of the endosymbiont resulted in a secondary gene transfer and a partial translocation of metabolic pathways (C: cyanobacterium; P: plastid; M: mitochondrium; N: nucleus, CER: chloroplast endoplasmic reticulum). 
Chlorophylls

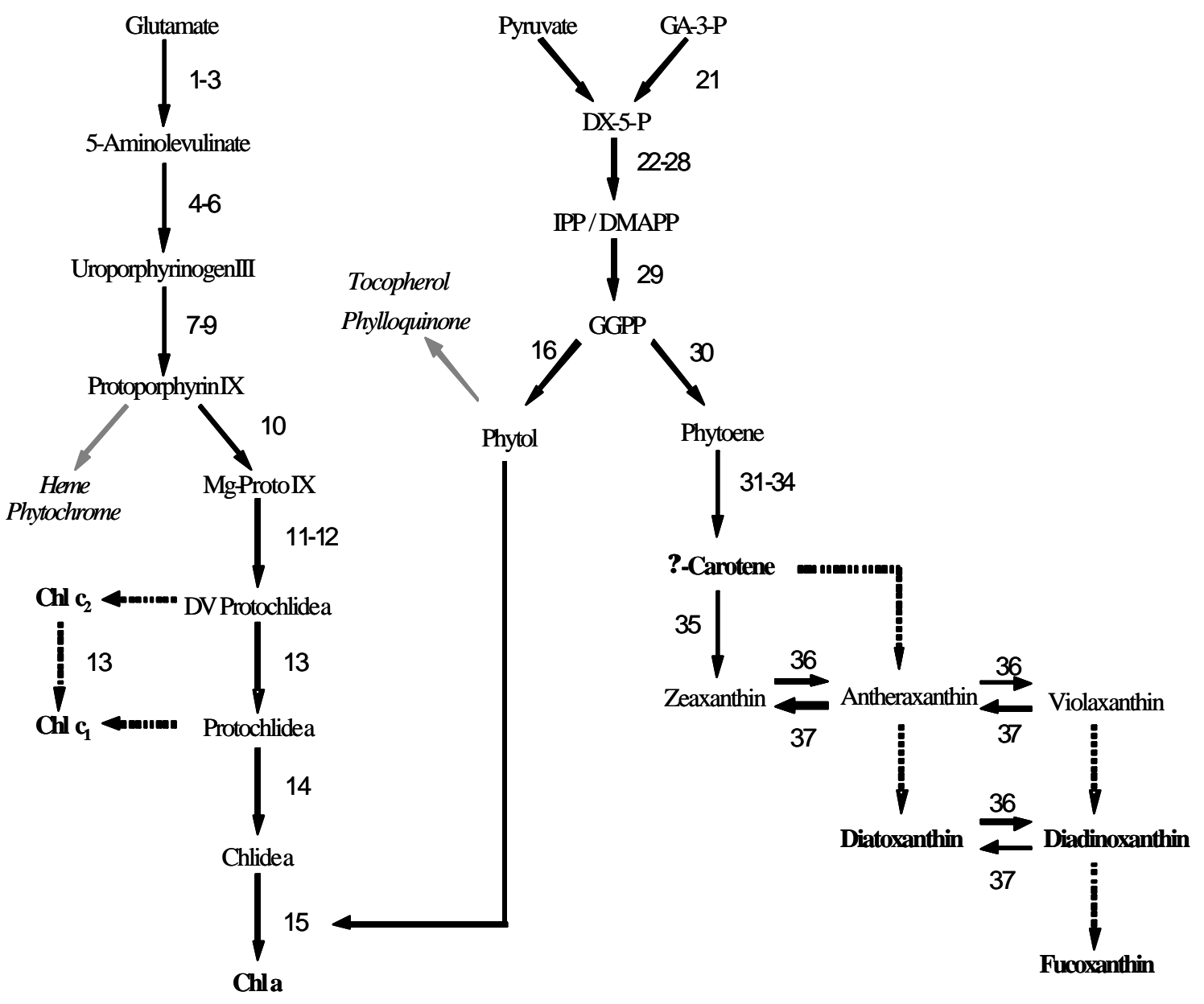

Carotenoids 


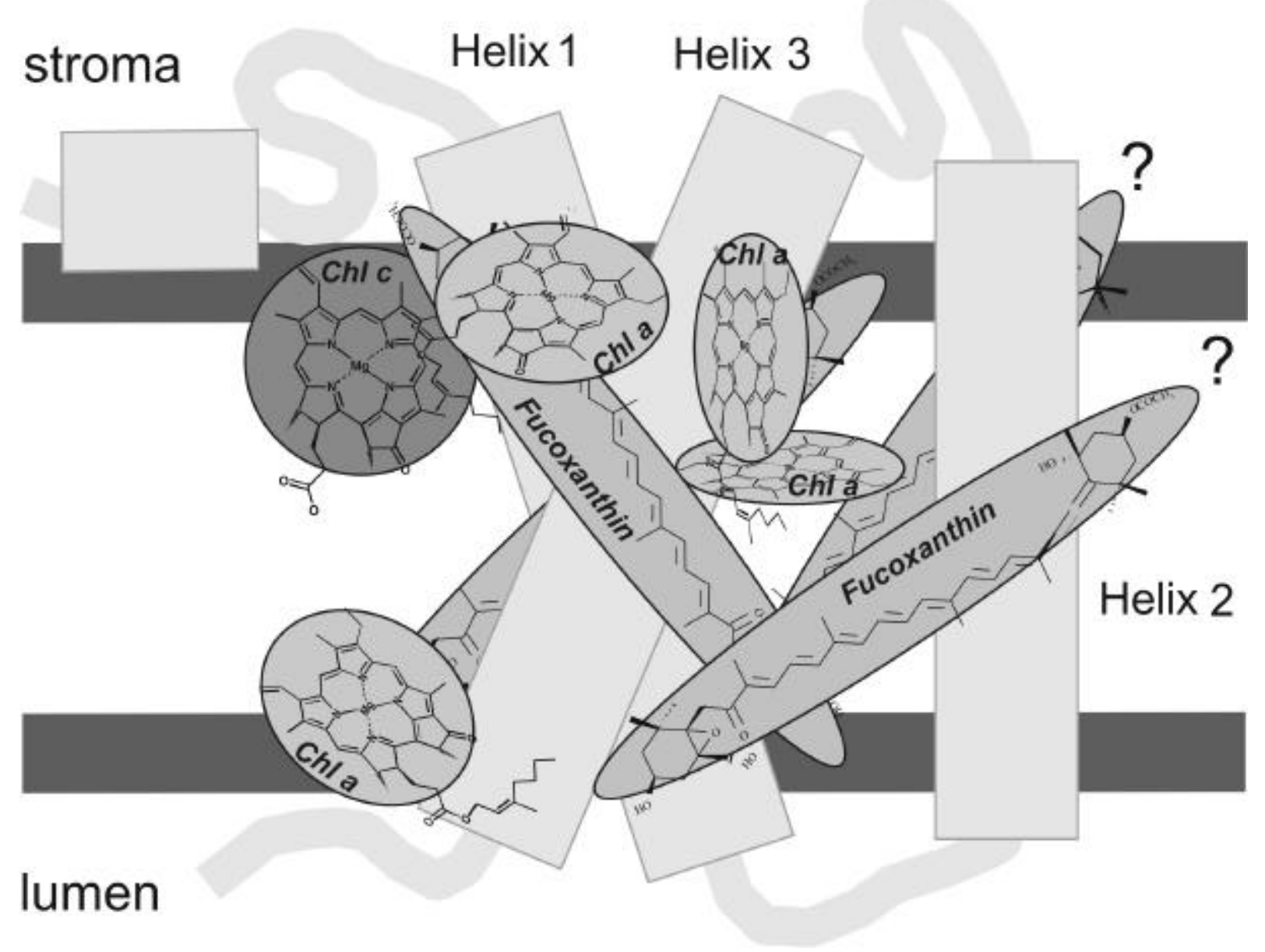

Figure 3: Model of the FCP including pigments. The secondary structure is based on sequence homology with LHC proteins (Eppard and Rhiel 1998) and pigments are arranged taking into account conserved binding sites as well as spectroscopic results (Papagiannakis et al. in press): $\mathrm{Chl} \mathrm{c}$ is located in close vicinity to $\mathrm{Chl}$ a and two fucoxanthins are arranged in the same way as luteins in LHCll. Note that due to the lack of data the porphyrin ring systems of the Chls are completely randomly oriented and due to little homology in the area of helix 2 no evidence is available for the binding sites of the two other fucoxanthin molecules (marked with a question mark). 


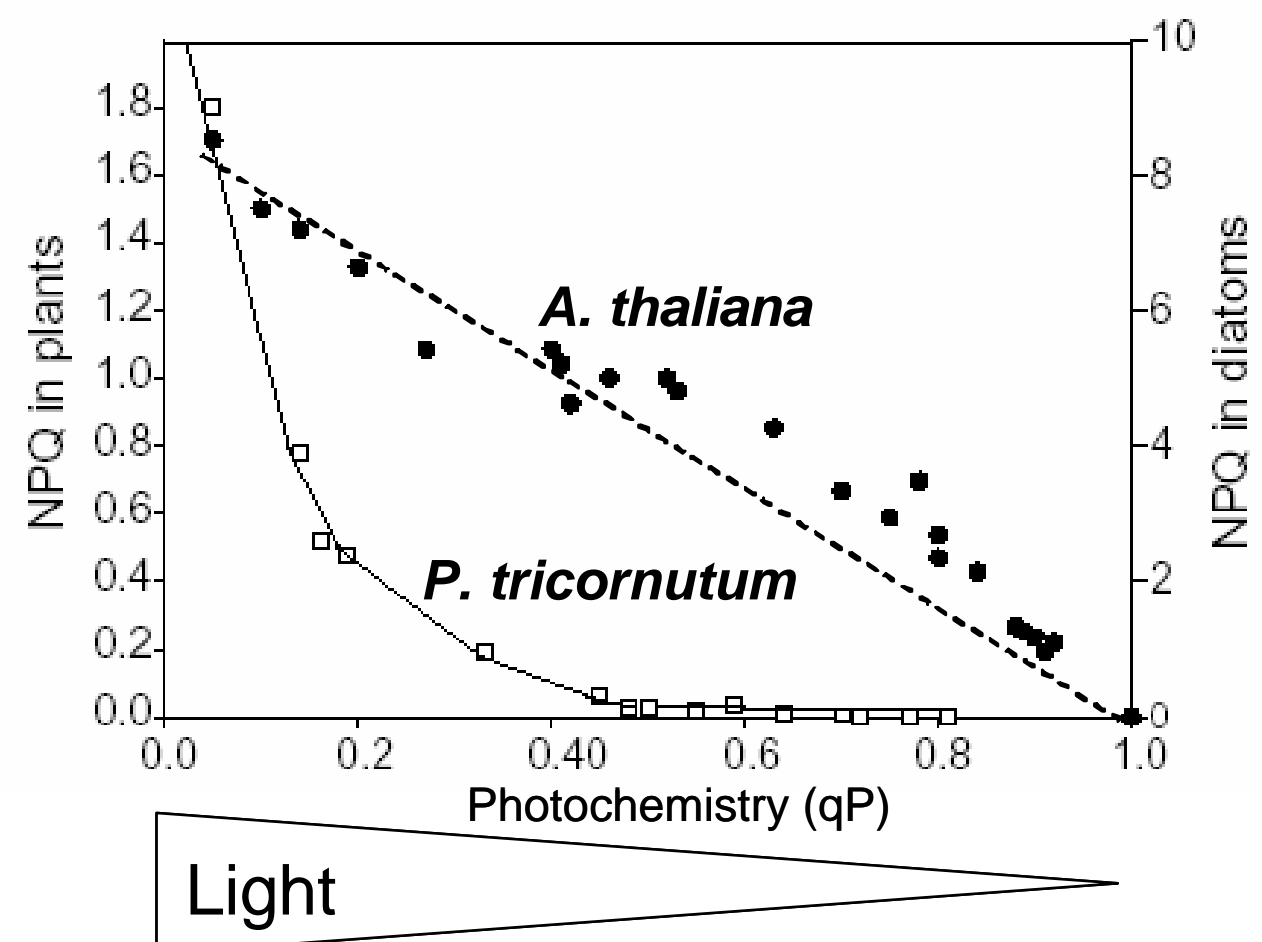

Figure 4: Relationship between photochemistry (qP) and photoprotective dissipation of excess energy (NPQ) in the diatom $P$. tricornutum (white squares) and the plant $A$. thaliana (leaf) (black circles). Modified from Ruban et al (2004). 


\section{Vx cycle}

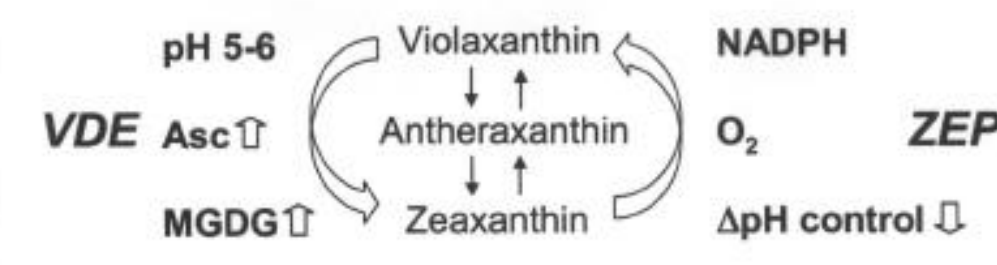

\section{Ddx cycle}

pH 5-7

NADPH

DDE Asc

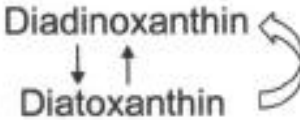

$\mathrm{O}_{2}$

DEP

MGDG 』

$\Delta \mathrm{pH}$ control 凹

Figure 5. Reaction sequence and enzymes of the violaxanthin and diadinoxanthin cycle. The $\mathrm{Vx}$ cycle is present in higher plants and green and brown algae, the Ddx cycle is found in diatoms, Dino-, Xantho- and Haptophyta. Fig. 5 also shows the cofactor requirements of the enzymes catalyzing the de-epoxidation reaction (VDE and DDE) and the epoxidation reaction (ZEP and DEP), respectively. Arrows behind the cofactors indicate whether high or low concentrations of the respective cofactors are needed for high enzyme activity. Fig. 8 also indicates that the proton gradient inhibits Dtx epoxidation (high ? pH control) whereas Zx epoxidation is unaffected by the presence of the trans-membrane ? pH. Fig. 8 furthermore depicts the $\mathrm{pH}$-range of the thylakoid lumen where VDE and DDE activity can be observed. 


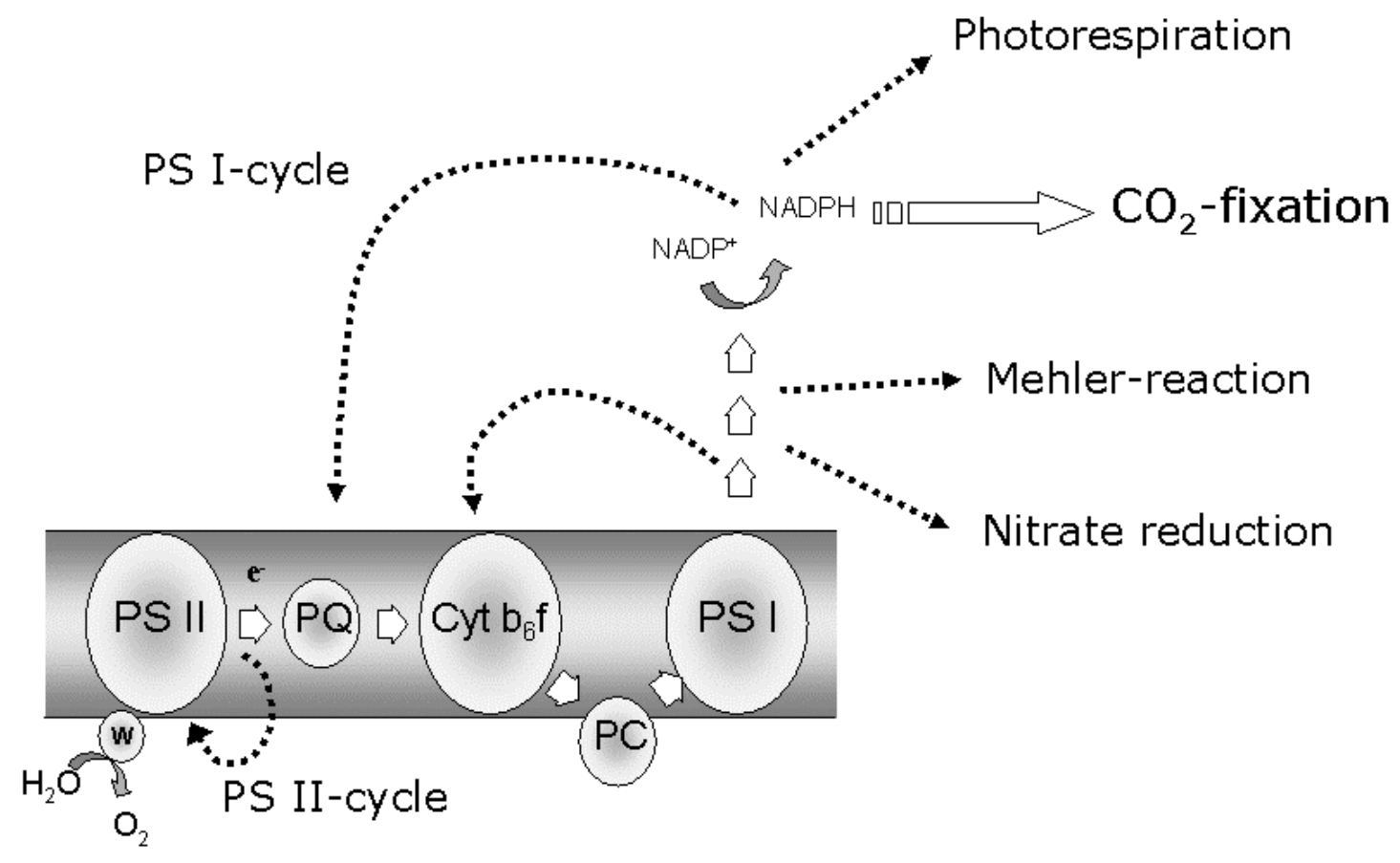

Figure 6: Scheme of the thylakoid membrane and the putative fate of photosynthetic electrons in the chloroplast 


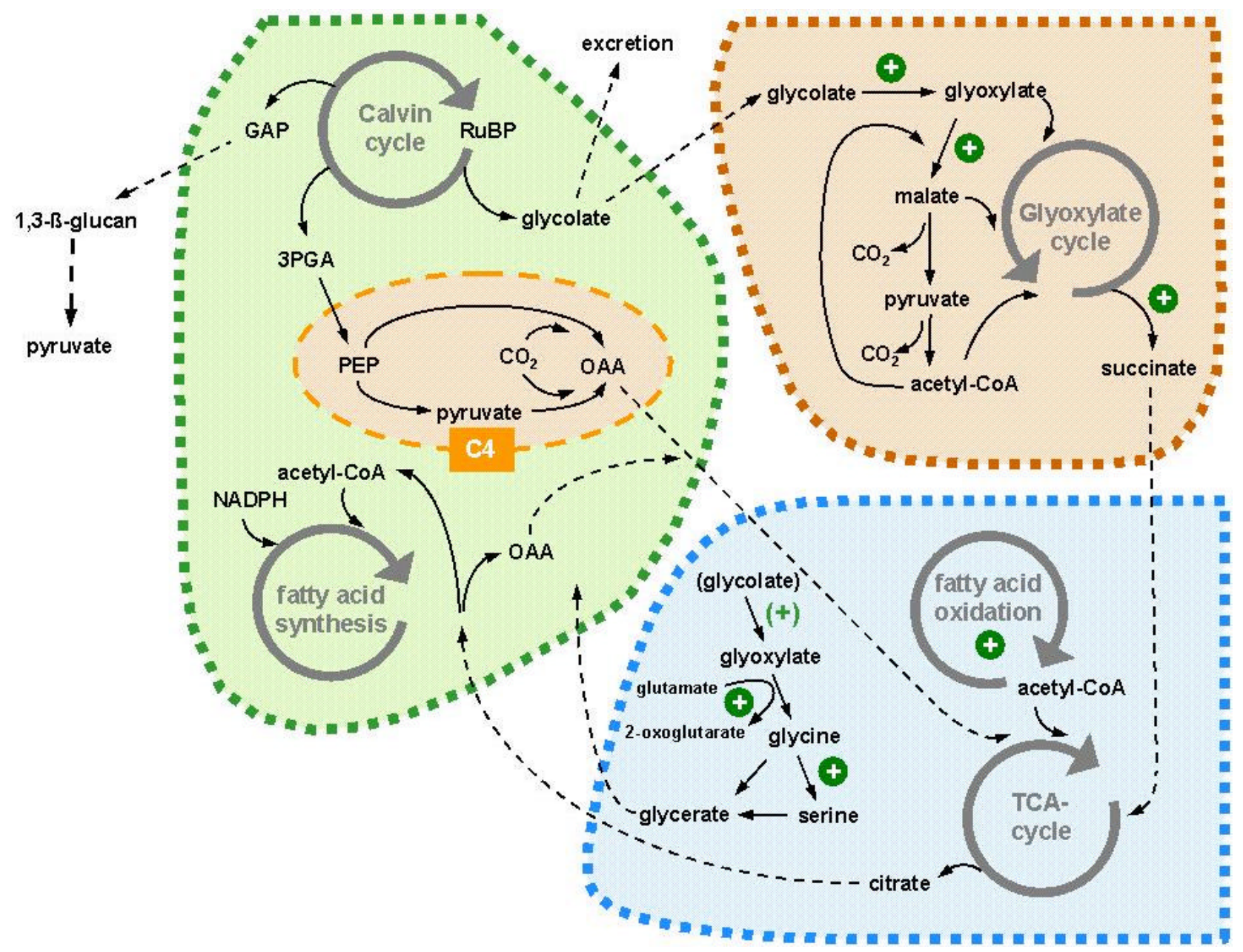

Figure 7: Metabolic pathways interconnecting the chloroplast, the mitochondrium and the peroxisome. In the case of diatoms the following pecularities deviate from the pattern of "green cells"

- no oxidative penthose phosphate pathway

- no B-oxidation in glyoxysomes

- no catalase in glyoxysomes

- C4-acid metabolism

- storage of carbohydrates in the cytosol

- existence of a complete urea cycle? 